\title{
Synthesis, DFT Calculation, and Antimicrobial Studies of Novel Zn(II), Co(II), Cu(II), and Mn(II) Heteroleptic Complexes Containing Benzoylacetone and Dithiocarbamate
}

\author{
Anthony C. Ekennia, ${ }^{1}$ Damian C. Onwudiwe, ${ }^{2,3}$ Lukman O. Olasunkanmi, ${ }^{2,3,4}$ \\ Aderoju A. Osowole, ${ }^{5}$ and Eno E. Ebenso ${ }^{2,3}$ \\ ${ }^{1}$ Department of Chemistry, Federal University Ndufu-Alike, Ikwo, PMB 1010, Abakaliki, Ebonyi, Nigeria \\ ${ }^{2}$ Material Science Innovation and Modelling (MaSIM) Research Focus Area, Faculty of Agriculture, Science and Technology, \\ North-West University (Mafikeng Campus), Private Bag X2046, Mmabatho, South Africa \\ ${ }^{3}$ Department of Chemistry, School of Mathematical and Physical Sciences, Faculty of Agriculture, Science and Technology, \\ North-West University (Mafikeng Campus), Private Bag X2046, Mmabatho 2735, South Africa \\ ${ }^{4}$ Department of Chemistry, Faculty of Science, Obafemi Awolowo University, Ile-Ife 220005, Nigeria \\ ${ }^{5}$ Inorganic Unit, Department of Chemistry, University of Ibadan, Ibadan, Nigeria
}

Correspondence should be addressed to Damian C. Onwudiwe; dcconwudiwe@gmail.com

Received 23 September 2015; Accepted 18 October 2015

Academic Editor: Concepción López

Copyright (C) 2015 Anthony C. Ekennia et al. This is an open access article distributed under the Creative Commons Attribution License, which permits unrestricted use, distribution, and reproduction in any medium, provided the original work is properly cited.

\begin{abstract}
Heteroleptic complexes of zinc(II), copper(II), manganese(II), and cobalt(II) of the types [MLL' $\left.\left(\mathrm{H}_{2} \mathrm{O}\right)_{2}\right] \cdot n \mathrm{H}_{2} \mathrm{O}_{\text {and }}\left[\mathrm{MLL}^{\prime}\right] \cdot n \mathrm{H}_{2} \mathrm{O}$ have been synthesized using sodium $N$-methyl- $N$-phenyldithiocarbamate $(\mathrm{L})$ and benzoylacetone $\left(\mathrm{L}^{\prime}\right)$. The metal complexes were characterized by elemental analysis, electrical conductance, magnetic susceptibility, infrared (IR), and UV-visible spectroscopic studies. The electrical conductance measurements revealed the nonelectrolytic nature of the synthesized complexes. The results of the elemental analyses, magnetic susceptibility measurements, and electronic spectra inferred that the Zn(II) complex adopted a four-coordinate geometry while the $\mathrm{Co}(\mathrm{II}), \mathrm{Cu}(\mathrm{II})$, and $\mathrm{Mn}$ (II) complexes assumed octahedral geometries. The IR spectra showed that the metal ions coordinated with the ligands via the S- and O-donor atoms. The geometry, electronic, and thermodynamic parameters of the complexes were obtained from density functional theory (DFT) calculations. The spin density distributions, relative strength of $\mathrm{H}$-bonds, and thermodynamic parameters revealed that the order of stability of the metal complexes is $\mathrm{Mn}<$ $\mathrm{Co}<\mathrm{Cu}>\mathrm{Zn}$. The agar diffusion methods were used to study the antimicrobial activity of the complexes against two Gram positive bacteria (S. aureus and S. pneumoniae), one Gram negative bacterium (E. coli), and two fungi organisms (A. niger and A. candida) and the complexes showed a broad spectrum of activities against the microbes.
\end{abstract}

\section{Introduction}

Medicinal inorganic chemistry has generated significant interest in the design of metal complexes as potential diagnostic and therapeutic agents. There are several metal complexes that are already in use for these purposes and this has encouraged further research on new metallodrugs such as metal-mediated antibiotics and anticancer and antiviral compounds [1]. The coordination chemistry of transition metal complexes with more than one type of ligands is of current interest because they serve as models for biochemical reactions [2]. Also, they provide new materials with useful properties such as magnetic exchange [3, 4], electrical conductivity [5], photoluminescence [6], and nonlinear optical property [7]. Mixed ligand complexes play important roles in biological processes like activation of enzymes by metals $[8,9]$ and storage and transport of active substances through membranes [10]. They have also been reported as being 
<smiles>O=CCC(=O)c1ccccc1</smiles>

Keto tautomer

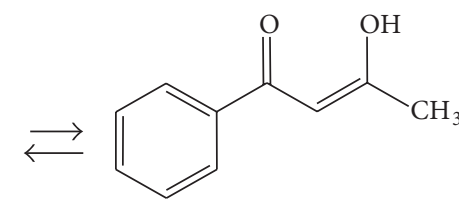

Enol tautomer
FIGURE 1: Keto-enol tautomerism of benzoylacetone ( $\beta$-diketone).

biologically active against pathogenic microorganisms [1113]. Metal complexes containing different ligands with oxygen and sulfur donor atoms have been reported in the literature, and among these highlights are the dithiocarbamates and $\beta$ diketones mixed ligand complexes [14-16].

The chemistry of $\beta$-diketones $\left(\mathrm{R}_{1} \mathrm{COCHR}_{3} \mathrm{COR}_{2}\right)$ has drawn a lot of interest in inorganic chemistry due to their varied coordination modes and their ability to exhibit ketoenol tautomerism (Figure 1) [17, 18]. Their tautomeric forms are as a result of prototropic shift of the hydrogen atom of the $\mathrm{CHR}_{3}$ group which is activated by the adjacent $\mathrm{C}=\mathrm{O}$ groups, leading to conjugate system [19]. Substitution has a pronounced effect on tautomeric forms as the presence of electron withdrawing groups or phenyl at the $\mathrm{R}_{1}$ and/or $\mathrm{R}_{2}$ position(s) increases enolisation while electron releasing substituents like alkyl and methoxy increased the keto tautomers [20-22]. Spectroscopic characterization (mostly infrared spectra) of various $\beta$-diketones has shown that these tautomers exist in equilibrium with each other [23]. $\beta$-Diketones metal complexes have been reported to possess several biological properties [24, 25]. Similarly, dithiocarbamates and their metal complexes have been widely studied because of their wide biological, industrial, agricultural, and chemical applications [26-34]. They have been used as nitrogen-oxygen trapping agents [26], chelating agents of heavy metals [27-29], vulcanizers, fungicides, lubricants, and catalysts [30]. They have also been used in medicine since the dithiocarbamate moiety has been found in a variety of biologically active molecules [30-35].

Herein, we report the synthesis, antimicrobial properties, and the DFT studies of some novel heteroleptic complexes involving $N$-methyl- $N$-phenyldithiocarbamate and benzoylacetone. The aim is to explore their potency as novel bactericidal and fungicidal agents and also study the electronic and thermodynamic properties of the heteroleptic systems generated due to the presence of the two different ligand molecules in a compound.

\section{Experimental}

2.1. Materials and Methods. Copper(II) sulphate pentahydrate, cobalt(II) sulphate heptahydrate, zinc(II) sulphate heptahydrate, manganese(II) nitrate hexahydrate, carbon disulfide, benzoylacetone, and $N$-methyl aniline (Aldrich) were used as received. Methanol and diethyl ether (Ace Chemicals) were used directly.

Elemental analyses (C, H, N, and S) were performed on an Elementar, Vario EL Cube, setup for CHNS analysis.
The measurements of the room temperature magnetic susceptibilities were performed using a Johnson Matthey magnetic susceptibility balance, and the diamagnetic corrections were calculated using Pascal's constant [36]. The molar conductivity of the complexes was conducted using a MC1 conductivity meter with a cell constant of 1.0 measured at $25^{\circ} \mathrm{C}$ [37]. Electronic absorption spectra of the solutions were recorded on a Perkin Elmer Lambda $40 \mathrm{UV}$-Vis spectrometer. FTIR spectra $\left(400-4000 \mathrm{~cm}^{-1}\right.$ region) were recorded on a Bruker alpha-P FTIR spectrometer.

\subsection{Synthesis}

2.2.1. Preparation of Metal Complexes of Benzoylacetone and $N$-Methyl-N-phenyldithiocarbamate. Sodium N-methyl-Nphenyldithiocarbamate was synthesized according to a published procedure [38]. Equimolar concentration of sodium $N$-methyl- $N$-phenyldithiocarbamate $(2.4 \mathrm{mmol}$, $0.5 \mathrm{~g})$ and benzoylacetone $(2.4 \mathrm{mmol}, 0.39 \mathrm{~g})$ was dissolved in ethanol and the solution was added to $2.4 \mathrm{mmol}$ of the respective metal salt $\left(\mathrm{CoSO}_{4} \cdot 7 \mathrm{H}_{2} \mathrm{O}, \mathrm{CuSO}_{4} \cdot 5 \mathrm{H}_{2} \mathrm{O}\right.$, $\mathrm{ZnSO}_{4} \cdot 7 \mathrm{H}_{2} \mathrm{O}$, or $\left.\mathrm{Mn}\left(\mathrm{NO}_{3}\right)_{2} \cdot 6 \mathrm{H}_{2} \mathrm{O}\right)$. Triethylamine $(0.3 \mathrm{~mL})$ was added in drops to the reaction mixture. The resultant mixture was stirred at room temperature for $3 \mathrm{~h}$. The metal complexes were obtained as precipitates which were filtered under vacuum and stored under silica gel. The proposed structures and the schematic presentation of the synthesis of the mixed complexes are presented in Figures 2 and 3.

Cobalt complex; (CoLL'): $\left[\mathrm{CoC}_{18} \mathrm{H}_{21} \mathrm{NS}_{2} \mathrm{O}_{4}\right]$ (Yield: 0.30 g, 86\%), Elemental analysis, Anal: C, 49.31; H, 4.84; N, 3.20; S, 14.62. Found: C, 49.28; H, 4.82; N, 3.17; S, 14.58. FTIR $\left(\mathrm{v} / \mathrm{cm}^{-1}\right): 3435 \mathrm{~b}, 3007 \mathrm{~m}, 2989 \mathrm{~m}, 2875 \mathrm{~m} \mathrm{1605s}, 1585 \mathrm{~s}, 1512 \mathrm{~s}$, $1462 \mathrm{~s}, 1432 \mathrm{~s}, 1256 \mathrm{~m}, 1243 \mathrm{~m}, 913 \mathrm{~s}, 432 \mathrm{~m}$. UV-Vis: 14930, 15580, 24940, 25010, and $28570 \mathrm{~cm}^{-1}$. Magnetic moment: 4.9 BM; Conductance $\left(\Omega^{-1} \mathrm{~cm}^{2} \mathrm{~mol}^{-1}\right): 59.5$.

Copper complex; $\left(\mathrm{CuLL}^{\prime}\right) \cdot \mathrm{H}_{2} \mathrm{O}$ : $\left[\mathrm{CuC}_{18} \mathrm{H}_{21} \mathrm{NS}_{2} \mathrm{O}_{4}\right] \cdot \mathrm{H}_{2} \mathrm{O}$ (Yield: 0.32 g, 92\%), Elemental analysis, Anal: C, 46.89; H, 5.04; N, 3.04; S, 13.91. Found: C, 46.84; H, 5.05; N, 3.03; S, 13.88. FTIR (v/cm $\left.{ }^{-1}\right): 3478 \mathrm{~b}, 3013 \mathrm{~m}, 2945 \mathrm{~m}, 2823 \mathrm{~m} \mathrm{1603s,}$ $1587 \mathrm{~s}, 1542 \mathrm{~s}, 1452 \mathrm{~s}, 1426 \mathrm{~s}, 1253 \mathrm{~m}, 1247 \mathrm{~m}, 907 \mathrm{~s}, 419 \mathrm{~m}$. UVVis: 14990, 25190, 29240, and $40320 \mathrm{~cm}^{-1}$. Magnetic moment: 2.00 BM; Conductance $\left(\Omega^{-1} \mathrm{~cm}^{2} \mathrm{~mol}^{-1}\right): 5.47$.

Zinc complex; $\left(\mathrm{ZnLL}^{\prime}\right) \cdot 2 \mathrm{H}_{2} \mathrm{O}:\left[\mathrm{ZnC}_{18} \mathrm{H}_{17} \mathrm{NS}_{2} \mathrm{O}_{2}\right] \cdot 2 \mathrm{H}_{2} \mathrm{O}$ (Yield: 0.30 g, 86\%), Elemental analysis, Anal: C, 48.59; H, 4.77; N, 3.15; S, 14.41. Found: C, 48.54; H, 4.73; N, 3.12; S, 14.28. FTIR $\left(\mathrm{v} / \mathrm{cm}^{-1}\right): 3480 \mathrm{~b}, 3001 \mathrm{~m}, 2921 \mathrm{~m}, 2811 \mathrm{~m} 1600 \mathrm{~s}$, 1580s, 1544s, 1433s, 1420s, 1263m, 1257m, 933s, 456m. UV-Vis: 24940, 29500, 33000, and $40320 \mathrm{~cm}^{-1}$. Magnetic moment: $0.12 \mathrm{BM}$; Conductance $\left(\Omega^{-1} \mathrm{~cm}^{2} \mathrm{~mol}^{-1}\right): 9.32$.

Manganese complex; $\left(\mathrm{MnLL}^{\prime}\right): \quad\left[\mathrm{MnC}_{18} \mathrm{H}_{21} \mathrm{NS}_{2} \mathrm{O}_{4}\right]$ (Yield: 0.32 g, 92\%), Elemental analysis, Anal: C, 49.76; H, 4.88; N, 3.23; S, 14.76. Found: C, 49.70; H, 4.83; N, 3.21; S, 14.73. FTIR (v/ $\left.\mathrm{cm}^{-1}\right): 3503 \mathrm{~b}, 3008 \mathrm{~m}, 2934 \mathrm{~m}, 2851 \mathrm{~m} 1612 \mathrm{~s}$, $1595 \mathrm{~s}, 1552 \mathrm{~s}, 1423 \mathrm{~s}, 1411 \mathrm{~s}, 1234 \mathrm{~m}, 1212 \mathrm{~m}, 907 \mathrm{~s}, 448 \mathrm{~m}$. UVVis: 11570, 15580, 24940, 29670, and $41150 \mathrm{~cm}^{-1}$. Magnetic moment: $5.82 \mathrm{BM}$; Conductance $\left(\Omega^{-1} \mathrm{~cm}^{2} \mathrm{~mol}^{-1}\right)$ : 43.3. 
<smiles>CC1=CC(=O)ON=C(c2ccccc2)S1</smiles>

Where $\mathrm{M}=\mathrm{Zn}$ (tetrahedral geometry)

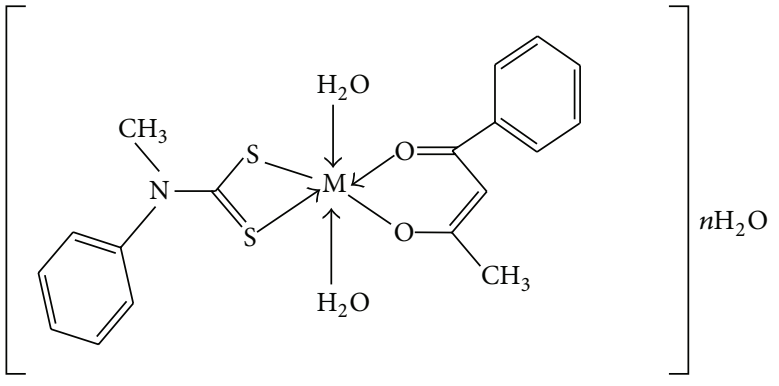

Where $\mathrm{M}=\mathrm{Cu}, \mathrm{Co}$, and $\mathrm{Mn}$ (octahedral geometry) and $n=0-1$

Figure 2: Proposed geometry of the mixed ligand complexes.

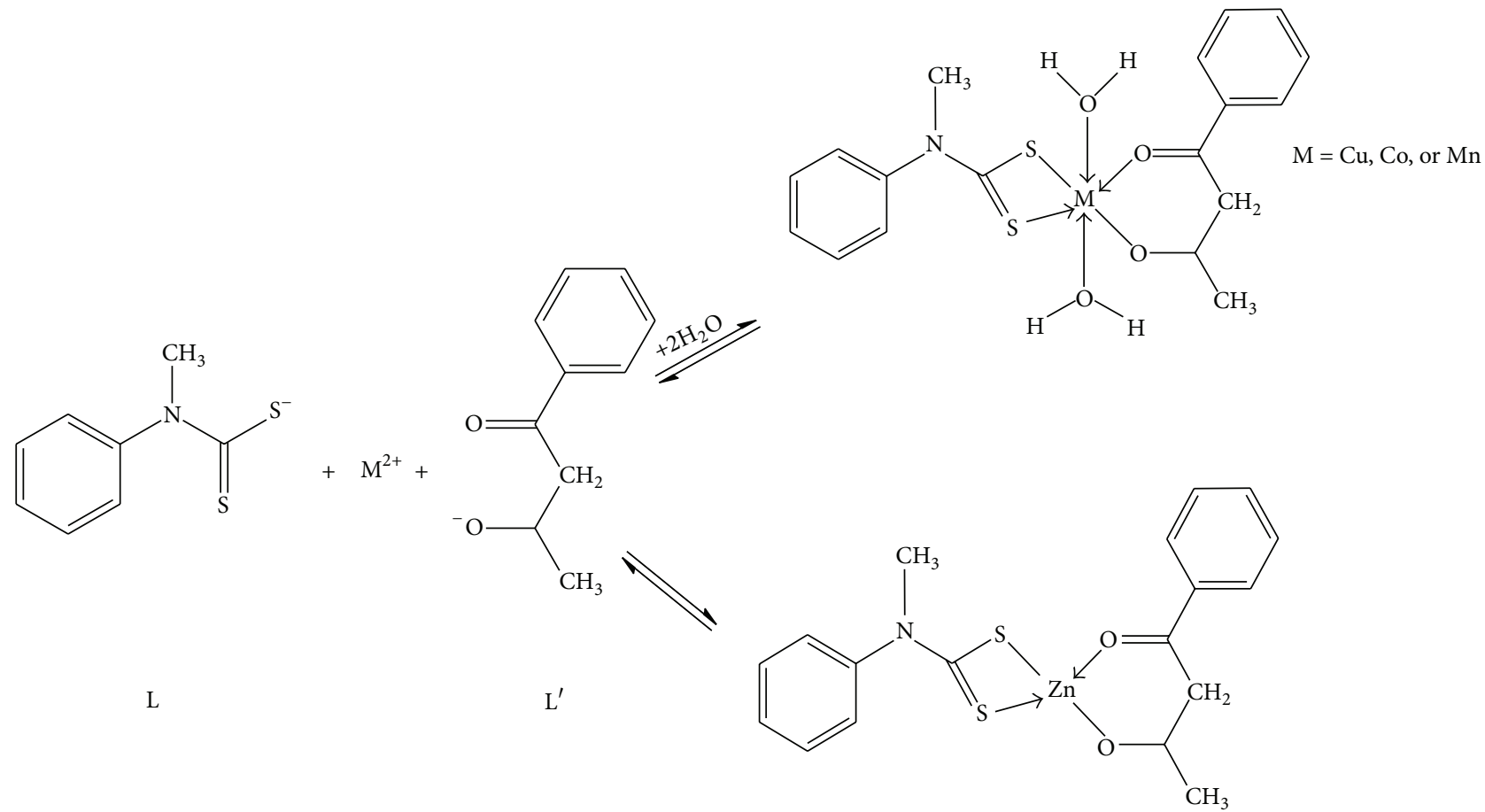

FIgURE 3: Schematic presentation of the synthesis of the complexes.

\section{DFT Computational Studies}

Geometry optimization and frequency calculations were carried out on the two ligands, that is, $N$-methyl- $N$-phenyldithiocarbamate $(\mathrm{L})$ and benzoylacetone $\left(\mathrm{L}^{\prime}\right)$, and their $\mathrm{Zn}(\mathrm{II}), \mathrm{Cu}(\mathrm{II}), \mathrm{Co}(\mathrm{II})$, and $\mathrm{Mn}(\mathrm{II})$ complexes. All the optimized structures were confirmed to correspond to the most stable ground state conformers by the absence of imaginary frequency in the force constant calculations. Since the ligands are expected to dissociate into their corresponding anions in solution, the optimized structures of the ligands are those of their singly charged anions. The density functional theory (DFT) method involving the Becke 3-parameter exchange functional together with the Lee-Yang-Parr correlation functional (B3LYP) $[39,40]$ was used for all the calculations. The B3LYP functional has been successfully used in some previous works for geometry optimization of transition metal complexes [41-44]. It has proven sufficient to produce acceptable geometry and spectroscopic parameters comparable to experimental crystallographic data for some transition metal complexes at moderate computational cost [44]. The $6-31+G(d, p)$ basis set was used for $C, H, N, O$, and $S$ atoms, while the metal ions were described by the LANL2DZ relativistic pseudopotential. The LANL2DZ relativistic pseudopotential has been found reliable for quantum chemical studies on transition metal complexes [43, 45-50]. It is a "double" quality basis set which uses the Duning D95 $\mathrm{V}$ basis set on the first-row atoms and Los Alamos ECP plus DZ on Na-Bi $[42,51-54]$. It has been reported to be computationally efficient and suitable for a variety of transition metal complexes [42, 55-57]. The placement of the ECP on transition metal ions via the use of the LANL2DZ basis set has been found to yield results at similar level of accuracy to the all-electron basis set, such as DZVP $[42,58]$. 
DFT computational model similar to the one used in the present work has been previously employed by Gorelsky et al. for theoretical description of some metal complexes of sulphur containing chelating resin [44].

All the ligands and metal complexes were modeled with Gaussview 5.0 software. Based on the results obtained from the magnetic moment experiments, a four-coordinate system was adopted for the ZnLL', while CuLL', CoLL', and MnLL' were modeled as six-coordinate systems each with two molecules of water as additional ligands. Gas phase geometry optimizations were carried out without symmetry constraint by using the Gaussian 09W software [59].

Geometry and electronic and thermodynamic parameters were obtained from the optimized geometries. The frontier molecular orbital (FMO) energies, the energy of the highest occupied molecular orbital, $E_{\mathrm{HOMO}}$, and the energy of the lowest unoccupied molecular orbitals, $E_{\mathrm{LUMO}}$, of the studied metal complexes are reported. The binding energy, $\mathrm{BE}$, was calculated for each of the metal complexes as the energy required to disassemble the metal complex into its constituent ligands and metal ion, equivalent to the energy difference for the reaction equation shown in Figure 3.

According to the equation shown in Figure 3, BE was calculated as

$$
\mathrm{BE}=E_{(\mathrm{M} \text {-complex })}-\left(E_{(\mathrm{L})}+E_{\left(\mathrm{L}^{\prime}\right)}+n E_{\left(\mathrm{H}_{2} \mathrm{O}\right)}+E_{\left(\mathrm{M}^{2+}\right)}\right),
$$

where $E_{(M-c o m p l e x)}$ is the energy of the metal complex $\left(\mathrm{ZnLL}^{\prime}\right.$, MnLL', CoLL', or CuLL'), $E_{\left(\mathrm{M}^{2+}\right)}$ is the energy of the metal ion $(\mathrm{Zn}(\mathrm{II}), \mathrm{Cu}(\mathrm{II}), \mathrm{Co}(\mathrm{II})$, or $\mathrm{Mn}(\mathrm{II}))$, and $E_{(\mathrm{L})}$ and $E_{\left(\mathrm{L}^{\prime}\right)}$ are the energies of the ligands $\mathrm{L}$ and $\mathrm{L}^{\prime}$, respectively. The constant $n=0$ for ZnLL' and equals 2 for other complexes. Other thermodynamic parameters such as the change in enthalpy $(\Delta H)$, entropy $(\Delta S)$, and Gibb's free energy $(\Delta G)$ of complexation were calculated according to the following equation:

$$
\begin{aligned}
\Delta H= & H_{(\text {M-complex })} \\
& -\left(H_{(\mathrm{L})}+H_{\left(\mathrm{L}^{\prime}\right)}+n H_{\left(\mathrm{H}_{2} \mathrm{O}\right)}+H_{\left(\mathrm{M}^{2+}\right)}\right), \\
\Delta S= & S_{(\text {M-complex })}-\left(S_{(\mathrm{L})}+S_{\left(\mathrm{L}^{\prime}\right)}+n S_{\left(\mathrm{H}_{2} \mathrm{O}\right)}+S_{\left(\mathrm{M}^{2+}\right)}\right), \\
\Delta G= & G_{(\text {M-complex })} \\
& -\left(G_{(\mathrm{L})}+G_{\left(\mathrm{L}^{\prime}\right)}+n G_{\left(\mathrm{H}_{2} \mathrm{O}\right)}+G_{\left(\mathrm{M}^{2+}\right)}\right),
\end{aligned}
$$

where $H_{i}, S_{i}$, and $G_{i}$ are the enthalpy, entropy, and free energy, respectively, of the corresponding species in the equation shown in Figure 3.

\section{Results and Discussion}

4.1. Electronic Spectra and Magnetic Moment. The absorption spectroscopy of the complexes was carried out as solid reflectance and recorded in wave numbers $\left(\mathrm{cm}^{-1}\right)$. The ultraviolet region of the electronic spectrum of the complexes was characterized by $\mathrm{n} \rightarrow \pi^{*}$ and $\pi \rightarrow \pi^{*}$ transitions of the ligands at 28570, 29240, 29500, 29670, 33000, 40000, 40320, and $41150 \mathrm{~cm}^{-1}$ [38].
The visible spectrum of copper(II) complexes is usually complicated due to the unsymmetrical band which arise from the Jahn-Teller distortions resulting in a number of overlapping bands. Jahn-Teller distortion in $\mathrm{Cu}$ (II) complexes is a consequence of the uneven distribution of electrons in the $\mathrm{e}_{\mathrm{g}}$ set of the $3 \mathrm{~d}$ orbitals [60]. Copper(II) complexes of a regular tetrahedral geometry usually have, in the visible region of the electronic spectrum, a single broad band below $10000 \mathrm{~cm}^{-1}$ of approximately $10^{2}$ molar intensity which is ascribed to ${ }^{2} \mathrm{~T}_{2} \rightarrow{ }^{2} \mathrm{E}$ transition, while regular octahedral copper(II) complexes have a single broad band above $10000 \mathrm{~cm}^{-1}$, with molar absorptivities of $10^{3} \mathrm{M}^{-1} \mathrm{~cm}^{-1}$, which is ascribed to ${ }^{2} \mathrm{E} \rightarrow{ }^{2} \mathrm{~T}_{2}$ transition. Copper(II) complexes with a squareplanar geometry, usually in its visible region of the electronic spectrum, show two bands between 15000 and $20000 \mathrm{~cm}^{-1}$ with molar absorptivities of $10^{2} \mathrm{M}^{-1} \mathrm{~cm}^{-1}[60,61]$. The copper complex showed a single absorption band at $14990 \mathrm{~cm}^{-1}$ and is ascribed to the ${ }^{2} \mathrm{E} \rightarrow{ }^{2} \mathrm{~T}_{2}$ transitions of an octahedral geometry. For copper complexes, the magnetic moment values are usually not used for prediction of the geometry but could give information on the number of metal centers involved in the complex. A moment of 1.9-2.2 BM is usually observed for mononuclear copper(II) complexes, regardless of stereochemistry, expectedly higher than the spin-only moment due to orbital contribution and spin-orbit coupling. A higher value may be seen in dinuclear copper complexes [62]. The copper(II) complex displayed a magnetic moment of 2.0 BM indicating its mononuclear nature.

Cobalt complex in a tetrahedral environment gives rise to three bands in the visible region of the electronic spectra that are ascribed to ${ }^{4} \mathrm{~A}_{2} \rightarrow{ }^{4} \mathrm{~T}_{2}(\mathrm{~F})\left(\nu_{1}\right),{ }^{4} \mathrm{~A}_{2} \rightarrow{ }^{4} \mathrm{~T}_{1}(\mathrm{~F})\left(\nu_{2}\right)$, and ${ }^{4} \mathrm{~A}_{2} \rightarrow{ }^{4} \mathrm{~T}_{1}(\mathrm{P})\left(v_{3}\right)$ transitions. The $\left(\nu_{1}\right)$ transition is usually not seen because it falls within the infrared region; $\left(\nu_{2}\right)$ transition usually appears in the near infrared region, while $\left(v_{3}\right)$ transition occurs in the visible region. The magnetic moment for cobalt(II) complex in a tetrahedral environment is within 4.20-4.60 BM but may be higher for stronger field ligands. Octahedral cobalt(II) complexes typically have three absorption bands in the visible region that are ascribed to ${ }^{4} \mathrm{~T}_{1} \mathrm{~g}(\mathrm{~F}) \rightarrow{ }^{4} \mathrm{~T}_{2} \mathrm{~g}(\mathrm{~F})\left(\nu_{1}\right),{ }^{4} \mathrm{~T}_{1} \mathrm{~g}(\mathrm{~F}) \rightarrow{ }^{4} \mathrm{~A}_{2} \mathrm{~g}(\mathrm{~F})\left(\nu_{2}\right)$, and ${ }^{4} \mathrm{~T}_{1} \mathrm{~g}(\mathrm{~F}) \rightarrow{ }^{4} \mathrm{~T}_{1} \mathrm{~g}(\mathrm{P})\left(\nu_{3}\right)$. This geometry could further be corroborated with magnetic moment value which falls in the range 4.7-5.2 BM [63]. The reflectance spectra of the cobalt complex showed three absorption bands at 14930, 15580, and $24940 \mathrm{~cm}^{-1}$ ascribed to ${ }^{4} \mathrm{~T}_{1} \mathrm{~g}(\mathrm{~F}) \rightarrow{ }^{4} \mathrm{~T}_{2} \mathrm{~g}(\mathrm{~F})\left(\nu_{1}\right),{ }^{4} \mathrm{~T}_{1} \mathrm{~g}(\mathrm{~F}) \rightarrow$ ${ }^{4} \mathrm{~A}_{2} \mathrm{~g}(\mathrm{~F}),\left(\nu_{2}\right)$, and ${ }^{4} \mathrm{~T}_{1} \mathrm{~g}(\mathrm{~F}) \rightarrow{ }^{4} \mathrm{~T}_{1} \mathrm{~g}(\mathrm{P}),\left(\nu_{3}\right)$, respectively, of an octahedral geometry $[36,64]$. The magnetic moment for the complex is $4.98 \mathrm{BM}$.

$\mathrm{Zn}$ (II) complexes usually do not have d-d absorption bands in the visible region due to the presence of completely filled $3 \mathrm{~d}$ orbitals but display metal $\rightarrow$ ligand transitions. Zinc(II) metal complexes are diamagnetic in nature with a magnetic moment below $0 \mathrm{BM}$ and mostly adopt a four-coordinate tetrahedral geometry [65]. The zinc complex showed a single charge transfer absorption band at $24940 \mathrm{~cm}^{-1}$, in the visible region and a magnetic moment of $0.12 \mathrm{BM}$. 
The Mn(II) complexes are characterized by weak spin forbidden transitions. This is due to the presence of a ${ }^{6} \mathrm{~S}$ ground term and a ${ }^{4} \mathrm{G}$ upper term. An octahedral Mn(II) complex is usually characterized by three weak absorption bands due to ${ }^{6} \mathrm{~A}_{1} \mathrm{~g} \rightarrow{ }^{4} \mathrm{~T}_{2} \mathrm{~g}(\mathrm{G}),{ }^{6} \mathrm{~A}_{1} \mathrm{~g} \rightarrow{ }^{4} \mathrm{E}_{\mathrm{g}}(\mathrm{G})$, and ${ }^{6} \mathrm{~A}_{1} \mathrm{~g} \rightarrow{ }^{4} \mathrm{~T}_{1} \mathrm{~g}$ transitions [66]. The manganese complex showed three weak absorption bands at 11570,15580 , and $24940 \mathrm{~cm}^{-1}$ typical of 6-coordinate octahedral geometry and are assigned to ${ }^{6} \mathrm{~A}_{1} \mathrm{~g} \rightarrow{ }^{4} \mathrm{~T}_{1} \mathrm{~g},{ }^{6} \mathrm{~A}_{1} \mathrm{~g} \rightarrow{ }^{4} \mathrm{~T}_{2} \mathrm{~g}(\mathrm{G})$, and ${ }^{6} \mathrm{~A}_{1} \mathrm{~g} \rightarrow{ }^{4} \mathrm{E}_{\mathrm{g}}(\mathrm{G})$ transitions, respectively. The effective magnetic moment of $\mathrm{Mn}$ (II) complexes is expected to be close to the spin-only value of $5.90 \mathrm{BM}$. Since the ground term is ${ }^{6} \mathrm{~A}_{1} \mathrm{~g}$, there is no orbital contribution. Consequently, an observed moment of $5.67 \mathrm{BM}$ for this complex indicates that it is high spin and complementary of octahedral geometry [67].

4.2. Infrared Spectra. The infrared spectra of the complexes gave bands between 400 and $4000 \mathrm{~cm}^{-1}$ from which information about the mode of coordination of the two ligands to the metal ions could be deduced. Bands due to $\mathrm{O}-\mathrm{H}$ stretching of the water of crystallization in the complexes appeared around $3503-3435 \mathrm{~cm}^{-1}$. The hydrogen stretching bands due to the aromatic phenyl ring, $v(\mathrm{Ar}-\mathrm{H})$, occurred as medium bands between 3013 and $3001 \mathrm{~cm}^{-1}$ in the complexes. The $\mathrm{C}-\mathrm{H}$ stretching bands for the alkyl groups of the dithiocarbamate moiety were observed around 2989$2811 \mathrm{~cm}^{-1}$. The $\mathrm{C}=\mathrm{O}$ stretching bands of the coordinated carbonyl group of the benzoylacetone in the enol form appeared as sharp bands between 1612 and $1600 \mathrm{~cm}^{-1}$, while the $\mathrm{C}-\mathrm{O}$ stretching vibration of the benzoylacetone and the $v\left(\mathrm{C}_{2}-\mathrm{N}\right)$ frequency of the dithiocarbamate ligand appeared as sharp band around $1263-1212 \mathrm{~cm}^{-1}$. The $\nu(\mathrm{C}=\mathrm{N})$ stretching bands of the dithiocarbamate moiety occurred as sharp bands in the range $1462-1411 \mathrm{~cm}^{-1}$. The $\nu(\mathrm{C}=\mathrm{S})$ frequency appeared as single bands around 933-907 in all the complexes and indicates a symmetrical bonding of the sulfur atoms of the dithiocarbamate ligand to the central metal ion. Stretching bands of the $v(\mathrm{M}-\mathrm{O})$ from the benzoylacetone moiety can be seen around $456-419 \mathrm{~cm}^{-1}$. The $\nu(\mathrm{M}-\mathrm{S})$ stretching bands for dithiocarbamate complexes usually fall below $400 \mathrm{~cm}^{-1}$ and thus could not be observed due to the spectral range of the measurements.

4.3. Conductivity Measurements. The metal complexes have molar conductivities $(\Lambda \mathrm{m})$ of $5.47-59.5 \mathrm{ohm}^{-1} \mathrm{~cm}^{2} \mathrm{~mol}^{-1}$ in DMSO and are therefore nonelectrolytes since a value above $60 \mathrm{ohm}^{-1} \mathrm{~cm}^{2} \mathrm{~mol}^{-1}$ is expected for $1: 1$ electrolyte [68]. Higher values of molar conductivities observed in the $\mathrm{Co}(\mathrm{II})$ and $\mathrm{Mn}$ (II) complexes compared to the $\mathrm{Zn}$ (II) and $\mathrm{Cu}$ (II) complexes may be due to the presence and absence of solvolysis in the complexes rather than ionic dissociation. Solvolysis is a special type of nucleophilic substitution $\left(\mathrm{S}_{\mathrm{N}} 1\right)$ or elimination where the nucleophile is a solvent molecule. DMSO which was used for conductivity measurement is a coordinating solvent and capable of causing solvolysis [69].
4.4. Quantum Chemical Studies. The gas phase optimized structures of the studied mixed ligand complexes are shown in Figure 4. The selected bond lengths that are salient to the results and discussion are listed in Figure 4. As shown in the equation in Figure 3, there are two different types of $\mathrm{M}-\mathrm{S}$ and $\mathrm{M}-\mathrm{O}$ bonds in the metal complexes, apart from the $\mathrm{M}-\mathrm{OH}_{2}$ bonds, which are only found in MnLL', CoLL', and CuLL'. For the purpose of discussion of results, the two different M$\mathrm{S}$ and $\mathrm{M}-\mathrm{O}$ bonds with which the central metal ion in each case binds with the ligands are designated as $\mathrm{M}-\mathrm{S}_{\mathrm{sp}^{2}}$ and $\mathrm{M}-$ $\mathrm{S}_{\mathrm{sp}^{3}}$ and $\mathrm{M}-\mathrm{O}_{\mathrm{sp}^{2}}$ and $\mathrm{M}-\mathrm{O}_{\mathrm{sp}^{3}}$. The results in Figure 4 show that the trend of the $\mathrm{M}-\mathrm{O}_{\mathrm{sp}^{2}}$ bond lengths in the studied complexes is $\mathrm{Zn}-\mathrm{O}_{\mathrm{sp}^{2}}>\mathrm{Cu}-\mathrm{O}_{\mathrm{sp}^{2}}>\mathrm{Co}-\mathrm{O}_{\mathrm{sp}^{2}}>\mathrm{Mn}-\mathrm{O}_{\mathrm{sp}^{2}}$, while the trend of the $\mathrm{M}-\mathrm{O}_{\mathrm{sp}^{3}}$ bond lengths is $\mathrm{Mn}-\mathrm{O}_{\mathrm{sp}^{3}}>$ $\mathrm{Cu}-\mathrm{O}_{\mathrm{sp}^{3}}>\mathrm{Co}-\mathrm{O}_{\mathrm{sp}^{3}}>\mathrm{Zn}-\mathrm{O}_{\mathrm{sp}^{3}}$. The trend of the $\mathrm{M}-\mathrm{O}_{\mathrm{sp}^{2}}$ bond lengths is the direct opposite of the order of the atomic radius of the central metal atoms, which implies that the M$\mathrm{O}_{\mathrm{sp}^{2}}$ bond lengths for the studied metal complexes do not have direct relationship with the atomic radius of the central metal. However, the shortest $\mathrm{M}-\mathrm{O}_{\mathrm{sp}^{2}}$ bond length observed for the MnLL' may be as a result of the presence of two vacant $3 \mathrm{~d}$ orbitals in the singlet electronic configurations of $\mathrm{Mn}^{2+}$ ion, which may inform optimum interactions with the pielectrons of the $\mathrm{sp}^{2}$ oxygen in the ligand.

The trend of the $\mathrm{M}-\mathrm{O}_{\mathrm{sp}^{3}}$ bond lengths for the sixcoordinate complexes is in line with the trend of the covalent radii of the central metal atoms. Meanwhile, the shortest M$\mathrm{O}_{\mathrm{sp}^{3}}$ bond length observed for the $\mathrm{ZnLL}^{\prime}$ may be due to the higher percentage of $s$ and $p$ orbitals in the tetrahedral configurations $\left(\mathrm{sp}^{3}\right)$ of the $\mathrm{Zn}^{2+}$ complex compared to the octahedral configurations in the other three complexes. This may allow for a higher degree of orbital interactions with the $\mathrm{sp}^{3} \mathrm{O}$ atom. The trends of the $\mathrm{M}-\mathrm{S}$ bond lengths however are not the same as the $\mathrm{M}-\mathrm{O}$ bond lengths. The $\mathrm{Co}-\mathrm{S}_{\mathrm{sp}^{2}}$ is the shortest, while the $\mathrm{Cu}-\mathrm{S}_{\mathrm{sp}^{3}}$ is the shortest of the $\mathrm{M}-\mathrm{S}_{\mathrm{sp}^{2}}$ and $\mathrm{M}-\mathrm{S}_{\mathrm{sp}^{3}}$ bonds, respectively. Another important observation in Figure 4 is the strength of the hydrogen bonds, $\mathrm{X}-\mathrm{-}-\mathrm{H}$ (where $-\mathrm{X}=-\mathrm{S}_{\mathrm{sp}^{3}}$, or $-\mathrm{O}_{\mathrm{sp}^{3}}$, and $\mathrm{H}$ is the $\mathrm{H}$ atom of the $\mathrm{H}_{2} \mathrm{O}$ molecules) with the decreasing strength in the order CuLL' > CoLL' > MnLL' for the $\mathrm{O}_{\mathrm{sp}^{3-}}--\mathrm{H}$ bonds. Only the MnLL' shows a satisfactory evidence of $\mathrm{S}_{\mathrm{sp}^{3-}}--\mathrm{H}$ bonds with bond lengths slightly above $2.9 \AA$. The $\mathrm{S}_{\mathrm{sp}^{3-}}$ $\mathrm{H}$ bonds in other complexes are longer than this value and therefore cannot be considered as to exhibit significant $\mathrm{H}-$ bond characters. The two $\mathrm{M}-\mathrm{OH}_{2}$ bond lengths in $\mathrm{MnLL}^{\prime}$, CoLL', and CuLL' follow the order of increasing atomic radii of the metal ions differing by $0.02 \AA$ in $\mathrm{MnLL}^{\prime}, 0.073 \AA$ in $\mathrm{CoLL}^{\prime}$, and $1.001 \AA$ in CuLL'. This reveals that one of the $\mathrm{H}_{2} \mathrm{O}$ molecules in the CuLL' is displaced farther away from the central $\mathrm{Cu}(\mathrm{II})$, which may be due to the Jahn-Teller distortion usually observed in $\mathrm{Cu}$ (II) complexes. The $\mathrm{M}-\mathrm{O}$ and $\mathrm{M}-$ $\mathrm{S}$ bond lengths observed for the studied metal complexes are in good agreement with what have been reported in the literature for similar bonds [70, 71].

The graphical surfaces of the electron density distributions of the HOMO, LUMO, and spin delocalization in the studied metal complexes are shown in Figure 5. The HOMO 


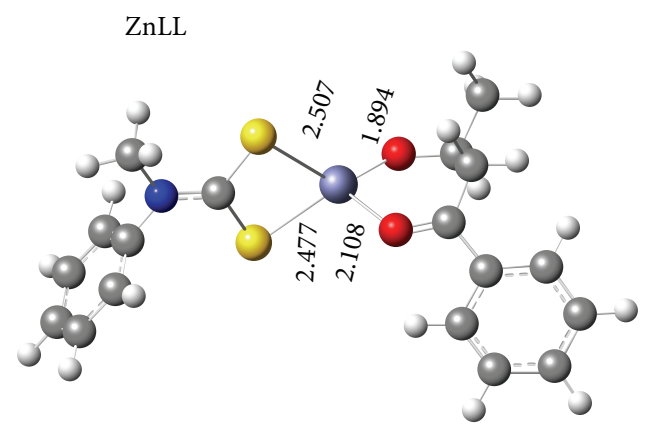

CoLL

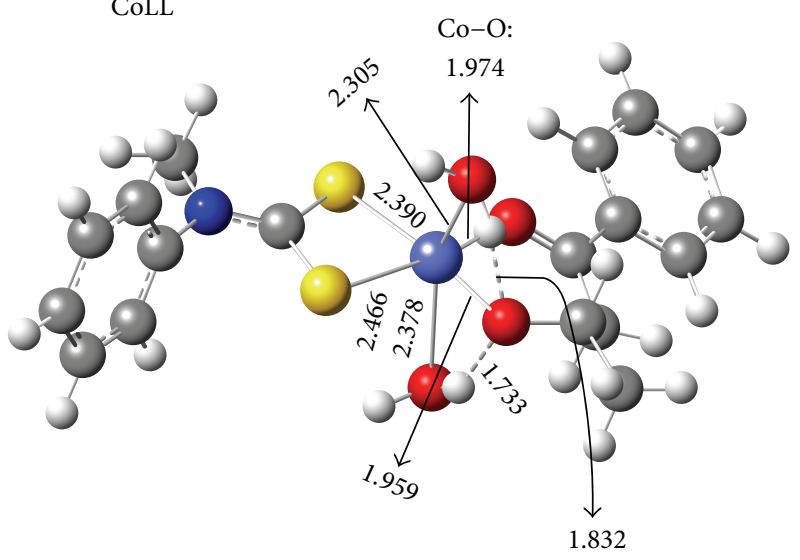

$\mathrm{H}$
$\mathrm{C}$
$\mathrm{N}$
$\mathrm{O}$

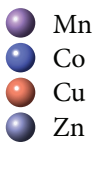

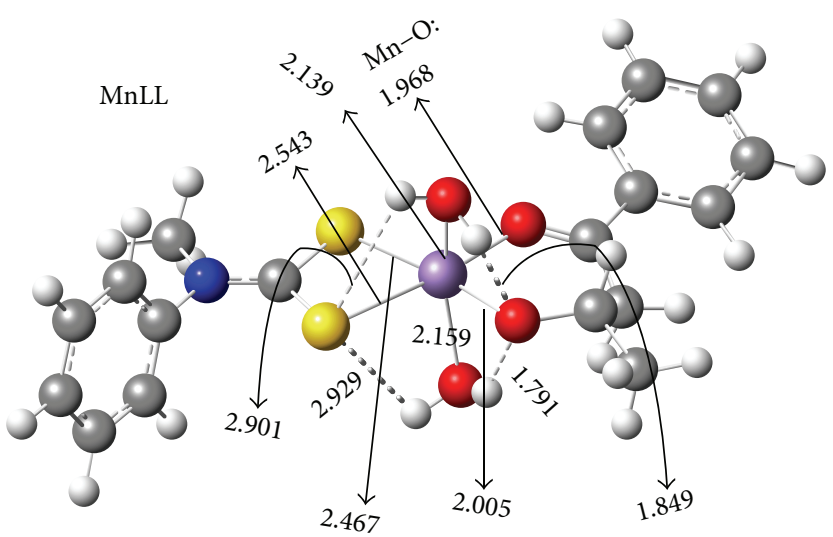
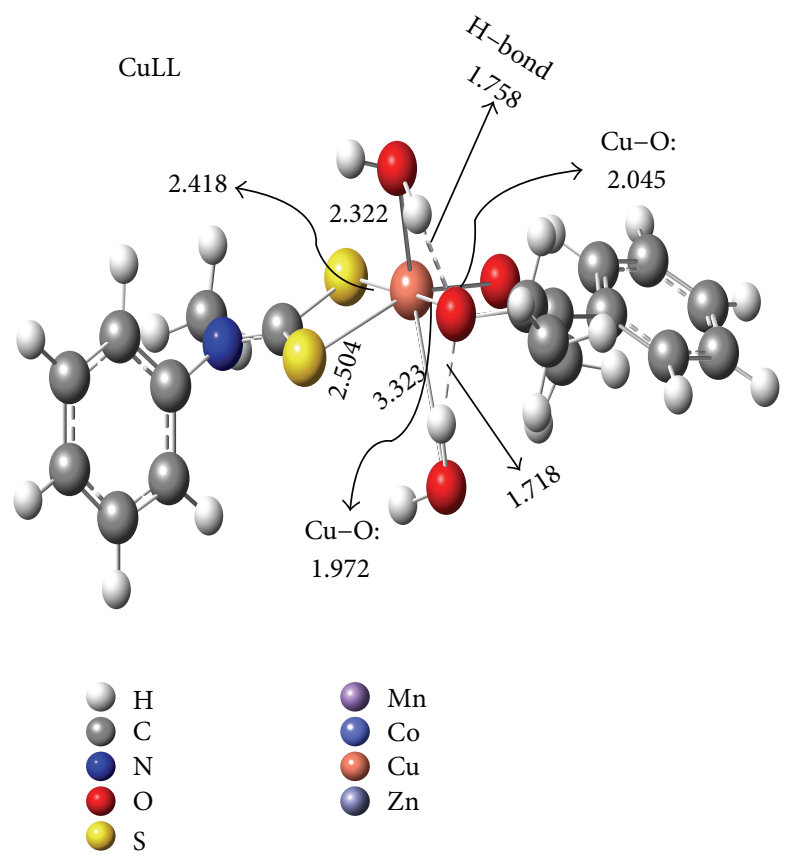

Figure 4: Optimized structures ZnLL', MnLL', CoLL', and CuLL' at B3LYP/6-31+G(d,p). Selected bond lengths ( $\AA$ ) that are relevant to the results and discussion are labeled.

of the $\mathrm{ZnLL}^{\prime}$ is essentially localized around the central $\mathrm{Zn}$ (II) ion and the neighboring coordination sites involving the atoms in the dithiocarbamate and alkoxyl groups of $\mathrm{L}$ and $\mathrm{L}^{\prime}$ ligands, respectively. Similar observations were made for the HOMO electron density distributions in MnLL', CoLL', and $\mathrm{CuLL}^{\prime}$, except that the $\mathrm{O}$ atoms of the water molecules also take part in the HOMO electron distributions. In all the studied metal complexes, the aromatic rings of the ligands do not make significant contributions to the HOMO. These electron density distributions of the HOMO surfaces suggest that the possible interactions of the studied metal complexes with an electrophilic agent will occur mainly around the central metal ions and the coordination sites and not around the aromatic rings. The electronegative $\mathrm{S}$ and $\mathrm{O}$ atoms that are directly bonded with the metal ions are capable of pulling electrons away from their respective adjacent aromatic rings, thereby decreasing the HOMO density around the rings. For all the studied metal complexes, the LUMO is essentially delocalized on the benzoylacetone ligand moiety. This implies that the most susceptible sites on the studied complexes for favourable interactions with an electron-rich species are located on the benzoylacetone unit.

The spin density distributions for the studied metal complexes are shown in Figure 5. For the complexes in which the central metal ion has " $n$ " unpaired electrons in the valence orbitals, the molecular orbitals are said to be characterized with these $n$ unpaired electrons such that a total spin density of $+n$ should be expected for the singly occupied molecular orbitals (SOMOs). It is expected that a large percentage of the spins are credited to the d-orbitals of the metal, since they provide the major contributions to the SOMOs. A fraction of the spin density is often delocalized to the ligand atoms and the spin population at the metal is usually less than the number of unpaired electrons in the valence atomic orbitals of the metal. In this regard, the difference between the number of unpaired electrons and the total spin density 
HOMO
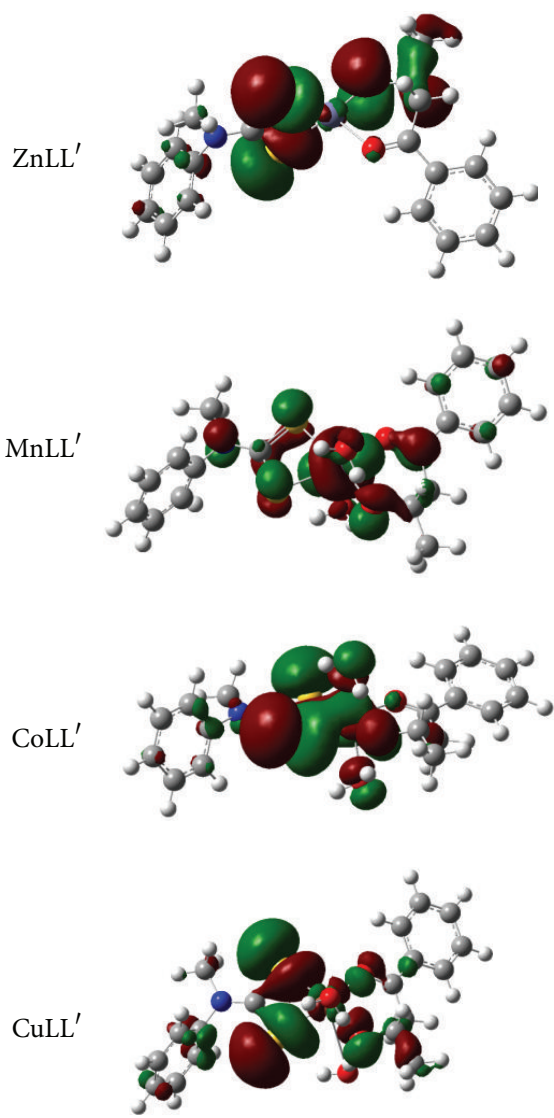

LUMO
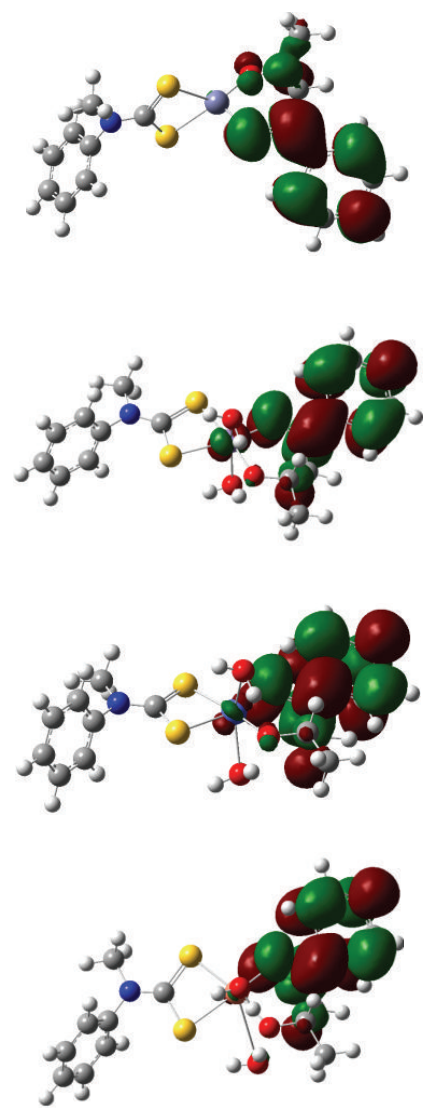

Spin density

N/A
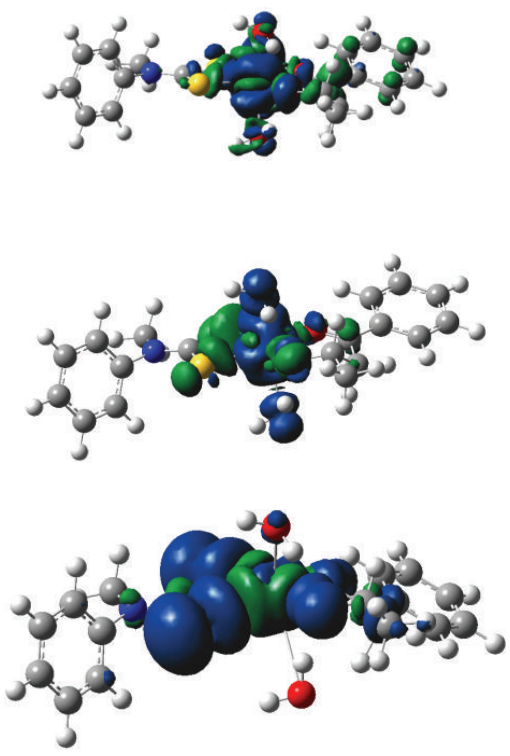

Figure 5: The graphical images of the HOMO, LUMO, and spin density electron distributions in ZnLL', MnLL', CoLL', and CuLL' at B3LYP/6-31+G(d,p)/LANL2DZ.

at the metal atom can be employed as a measure of the degree of covalent character of the metal-ligand bonds [72, 73]. Therefore, spin density distribution could be a reliable parameter for predicting the relative strength of metal-ligand covalent bonds.

The higher the spin density extended to a ligand atom, the stronger the covalent bond between that atom and the central metal ion containing the unpaired electron(s). With the spin density distribution analyses, a nonbias comparative strength of similar metal-ligand covalent bonds in a family of complexes can be deduced irrespective of the atomic or covalent radii of the metal ions which can bring about a relatively longer or shorter bond length that may not correlate directly with the relative strength of the bonds.

Since $\mathrm{Zn}(\mathrm{II})$ is a $\mathrm{d}^{10}$ system in which all the electrons are paired, no residual spin is expected and, thus, the results obtained for the ZnLL' showed no spin density. The results in Figure 5 reveal a clear localization of the spin density at the central metal ions in $\mathrm{MnLL}^{\prime}, \mathrm{CoLL}^{\prime}$, and CuLL', which is in agreement with the presence of unpaired electron in the respective d-orbitals of the metal ions. The spin densities are also extended to the $\mathrm{S}$ and $\mathrm{O}$ atoms of the organic ligands and water molecules bonded to the central metal ions. The involvement of the ligand atoms that are around the coordination sites in the spin density distributions is more pronounced for CuLL' than CoLL ${ }^{\prime}$ and MnLL', with the $\mathrm{Mn}$ (II) ion showing the least delocalization of the unpaired electron spin onto the ligand molecular orbitals. The percentage contributions of some selected atoms to the spin density distributions were calculated as the ratio of the square of the Mulliken atomic spin density for an atom to the sum of the square of Mulliken spin density for all atoms and the results are presented in Table 1. The results showed that the percentage spin density on the central metal ions is in the order $\mathrm{Mn}$ (II) $>\mathrm{Co}$ (II) $>\mathrm{Cu}$ (II), which may be due to the presence of 2, 1 , and 0 empty d-orbital(s) in $\mathrm{Mn}$ (II), $\mathrm{Co}(\mathrm{II})$, and $\mathrm{Cu}(\mathrm{II})$, respectively. In other words, vacant $\mathrm{d}$ orbitals in the electronic configurations of the metal ion may serve as the hosts for the delocalized spin density and reduce the percentage of the spin density extended to the adjacent atoms. It can be inferred from the results in Table 1 that the $\mathrm{d}$-orbital that hosts the unpaired electron in CuLL ${ }^{\prime}$ complex mixes better with the atomic orbitals of the ligands than the dorbitals hosting the unpaired electrons in CoLL' and MnLL' complexes. The results suggest further that the decreasing strength of the covalent bonds between the central metal ion 
TABLE 1: *Atomic percentage contributions to the spin density delocalization derived from the Mulliken atomic spin density values.

\begin{tabular}{lccccccccc}
\hline Complex & $\mathrm{M}$ & $\mathrm{O}_{\mathrm{sp}^{2}}$ & $\mathrm{O}_{\mathrm{sp}^{3}}$ & $\mathrm{O}\left(\mathrm{OH}_{2}\right)$ & $\mathrm{N}$ & $\mathrm{S}_{\mathrm{sp}^{2}}$ & $\mathrm{~S}_{\mathrm{sp}^{3}}$ & $\mathrm{C}\left(-\mathrm{CS}_{2}-\right)$ & $\mathrm{C}_{\mathrm{alp} / \mathrm{ar}}$ \\
\hline MnLL' & 99.81 & 0.00080 & 0.03053 & 0.00929 & 0.00488 & 0.00388 & 0.00254 & 0.13575 & $0.00351^{\text {ar }}$ \\
CoLL' $^{\text {alp }}$ & 96.80 & 0.00013 & 0.52223 & 0.04193 & 0.00151 & 0.44764 & 2.09192 & 0.06274 & $0.00276^{\text {alp }}$ \\
CuLL' $^{3}$ & 33.07 & 0.00149 & 23.72 & 0.98211 & 0.01081 & 39.84 & 0.00118 & 0.03101 & $0.11547^{\text {alp }}$ \\
\hline
\end{tabular}

* Percentage contributions by atom were calculated as the ratio of square of Mulliken spin density for an atom and the sum of square of Mulliken spin density for all atoms in the molecule. $\mathrm{M}=\mathrm{Mn}, \mathrm{Co}$, or $\mathrm{Cu} ; \mathrm{C}\left(-\mathrm{CS}_{2}-\right)$ is the carbon atom of the dithiocarbamate group. Highest contributions from the carbon atoms farther from the coordination sites were found on an aromatic/aliphatic carbon of the benzoylacetone ligand: ar = highest contribution from an aromatic carbon; alp = highest contribution from an aliphatic.

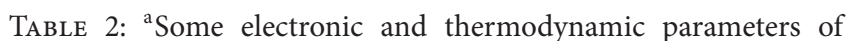
ZnLL', MnLL', CoLL', or CuLL'.

\begin{tabular}{lcccc}
\hline Parameters & ZnLL $^{\prime}$ & MnLL $^{\prime}$ & CoLL $^{\prime}$ & CuLL $^{\prime}$ \\
\hline$E_{\text {HOMO }}(\mathrm{eV})$ & -5.62 & -5.01 & -5.43 & -5.59 \\
$E_{\text {LUMO }}(\mathrm{eV})$ & -2.40 & -2.12 & -2.20 & -2.93 \\
$\mu($ Debye $)$ & 4.39 & 0.81 & 1.58 & 3.57 \\
$\mathrm{BE}(\mathrm{kcal} / \mathrm{mol})$ & -394.16 & -299.11 & -381.26 & -418.24 \\
$\Delta H(\mathrm{kcal} / \mathrm{mol})$ & -394.48 & -301.71 & -383.49 & -419.98 \\
$\Delta S(\mathrm{cal} / \mathrm{mol})$ & -68.06 & -147.66 & -144.23 & -134.10 \\
$\Delta G(\mathrm{kcal} / \mathrm{mol})$ & -374.18 & -257.68 & -340.49 & -380.00 \\
\hline
\end{tabular}

${ }^{a}$ All thermodynamic parameters are corrected for zero-point and thermal energies at $298 \mathrm{~K}$. Thermodynamic data for monatomic $\mathrm{M}^{2+}(\mathrm{M}=\mathrm{Zn}, \mathrm{Mn}$, $\mathrm{Co}$, and $\mathrm{Cu}$ ) ions were obtained from B3LYP/LANL2DZ theory.

in each case and the ligand atoms involved in coordination with the metal ion is $\mathrm{CuLL}^{\prime}>\mathrm{CoLL}^{\prime}>\mathrm{MnLL}^{\prime}$.

Some electronic and thermodynamic parameters were calculated for the metal complexes and the results are listed in Table 2. The frontier molecular orbital energy parameters such as the $E_{\mathrm{HOMO}}, E_{\mathrm{LUMO}}$, and $\Delta E_{\mathrm{LUMO}}$-HOMO are often used as reactivity or stability indices. A high value of $E_{\mathrm{HOMO}}$ implies better tendency of a molecule to donate its most loosely bound electron to the appropriate orbitals of an acceptor molecule. The decreasing order of $E_{\mathrm{HOMO}}$ of the studied metal complexes is $\mathrm{MnLL}^{\prime}>\mathrm{CoLL}^{\prime}>\mathrm{CuLL}^{\prime}>$ $\mathrm{ZnLL}^{\prime}$ which implies that the $\mathrm{Zn}^{2+}$ complex has the highest tendency to donate its most energetic electron to a suitable orbital of an acceptor molecule. The $E_{\mathrm{LUMO}}$ is a measure of the tendency of a molecule to accept electrons from the appropriate orbital of a donor species. The lower the $E_{\mathrm{LUMO}}$ the better the chance of electron acceptance by the molecule. The values of the $E_{\mathrm{LUMO}}$ listed in Table 2 for the studied complexes are in the order MnLL'>CoLL'> ZnLL' > CuLL', which implies that the CuLL' has the highest tendency to accept electrons from the appropriate occupied orbitals of an electron-donating species. The values of some thermodynamic parameters such as $\mathrm{BE}, \Delta H, \Delta S$, and $\Delta G$ for the studied metal complexes are reported in Table 2. The negative values of the $\mathrm{BE}$ in Table 2 indicate that the products of the reaction depicted by the equation shown in Figure 3 are more stable than the reactants. In other words, high amount of energy is required to split the metal complexes into their constituent metal ions and ligands, which is an indication of favourable formation of the complexes. The magnitudes of the $\mathrm{BE}$ values show that the CuLL' complex requires the highest amount of energy to break it into the constituent ligands and $\mathrm{Cu}^{2+}$ ion, making it the most stable complex. The negative values of $\Delta H$ imply that the reactions leading to the formation of the metal complexes are exothermic. The results in Table 2 also show that the $\Delta G$ values for the formation of the metal complexes are negative, which imply that the formation of the metal complexes is a spontaneous reaction. The order of spontaneity for the formation of the six-coordinate complexes is $\mathrm{CuLL}^{\prime}>\mathrm{CoLL}^{\prime}>\mathrm{MnLL}^{\prime}$, which suggests that the CuLL' is the most stable complex. This is in agreement with the relative strength of the metal-ligand covalent bonds deduced from the spin density distribution analyses and the strength of the H-bonds involved in the optimized structures of the metal complexes. The overall trend of the stability of the metal complexes observed in the present study, that is, $\mathrm{Mn}<\mathrm{Co}<\mathrm{Cu}>\mathrm{Zn}$, is in good agreement with the observation of Irving and Williams on the complexes of some first-row transition metals regardless of the nature of the ligand involved and the number of coordinated ligands [74]. Similar trend was also observed in the work of Luther et al. on the experimental stability constants of metal (bi)sulfide complexes of some first-row transition metals [75].

\section{Biological Studies}

5.1. Antimicrobial Screening. The assay was carried out on the metal(II) complexes using agar diffusion technique [76]. The surface of the agar in a Petri dish was uniformly inoculated with $0.3 \mathrm{~mL}$ of 18 hour-old test bacteria/fungus culture. Using a sterile cork borer, $6 \mathrm{~mm}$ wells were bored into agar. Then $0.06 \mathrm{~mL}$ of $10 \mathrm{mg} / \mathrm{mL}$ concentration of each metal complex in DMSO was introduced into the wells and the plates were allowed to stand on bench for $30 \mathrm{~min}$ before incubation at $37^{\circ} \mathrm{C}$ for $24 \mathrm{~h}$. After this, the inhibitory zones (in $\mathrm{mm}$ ) were taken as a measure of antibacterial and antifungal activity and presented in Table 3. The experiments were conducted in duplicate and streptomycin and fluconazole were used as the reference drug for the test bacteria and fungi, respectively.

The test compounds were screened against two Gram positive bacteria ( $S$. aureus and S. pneumoniae), one Gram negative bacterium (E. coli), and two fungi organisms ( $A$. niger and $A$. candida). The results presented in Table 3 and Figure 6 show that the test compounds have a low to high antimicrobial activity against the microbes. The CuLL' and ZnLL' complexes exhibited $83.7 \%$ activity of streptomycin against $E$. coli. The ZnLL' exhibited $72 \%$ and $80.5 \%$ activity 
TABLE 3: Summary of antimicrobial screening of the mixed ligand complexes.

\begin{tabular}{|c|c|c|c|c|c|}
\hline Name & S. aureus & S. pneumoniae & E. coli & A. candida & Aspergillus niger \\
\hline$\left[\mathrm{CoLL}^{\prime}\right]$ & $16.3 \pm 0$ & $12.0 \pm 0.1$ & $19.0 \pm 0.2$ & $11.0 \pm 0.1$ & $10.0 \pm 0.03$ \\
\hline$\left[\mathrm{MnLL}^{\prime}\right]$ & $\mathrm{R}$ & $\mathrm{R}$ & $8.0 \pm 0.4$ & $5.2 \pm 0.7$ & $13.0 \pm 0.7$ \\
\hline$\left[\mathrm{CuLL}^{\prime}\right]$ & $13.0 \pm 0.01$ & $18.0 \pm 0.1$ & $15.0 \pm 0.3$ & $20.1 \pm 0.02$ & $15.3 \pm 0.01$ \\
\hline$\left[\mathrm{ZnLL}^{\prime}\right]$ & $11.5 \pm 0.03$ & $13.0 \pm 1.4$ & $20.2 \pm 0.12$ & $16.0 \pm 0$ & $18.0 \pm 0.1$ \\
\hline Streptomycin & $23.2 \pm 0.1$ & $23.2 \pm 0.03$ & $25.1 \pm 0$ & - & - \\
\hline Fluconazole & - & - & - & $24.0 \pm 0.1$ & $25.0 \pm 0$ \\
\hline DMSO & $\mathrm{R}$ & $\mathrm{R}$ & $\mathrm{R}$ & $\mathrm{R}$ & $\mathrm{R}$ \\
\hline
\end{tabular}

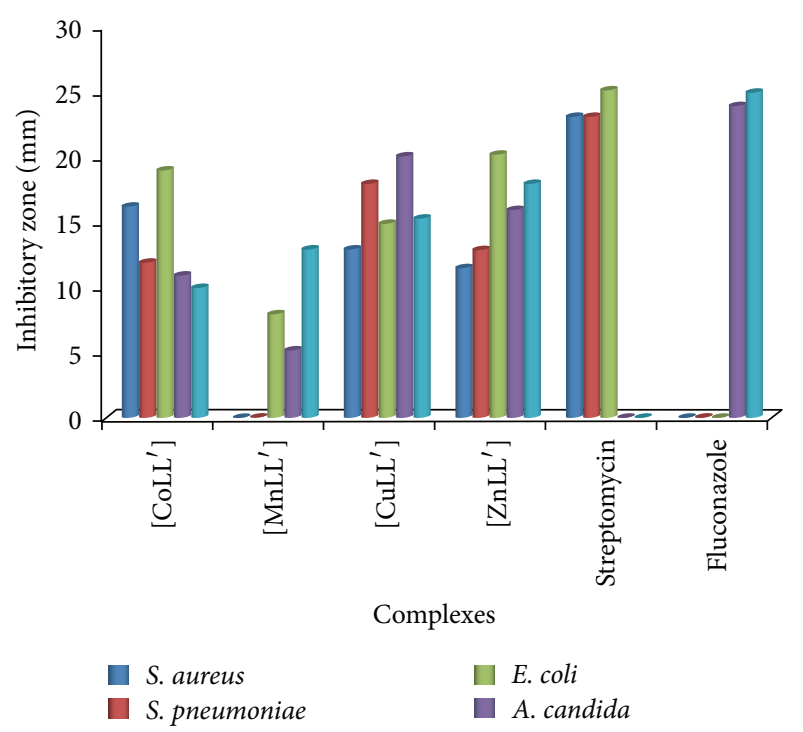

FIGURE 6: Histogram presentation of antimicrobial activity of the mixed ligand complexes.

compared to fluconazole against $A$. niger and A. candida, respectively. Generally, the ZnLL' complex showed the overall best antimicrobial character among the test compounds.

\section{Conclusions}

New heteroleptic complexes of $\mathrm{Zn}(\mathrm{II}), \mathrm{Cu}(\mathrm{II}), \mathrm{Mn}(\mathrm{II})$, and $\mathrm{Co}$ (II) derived from the mixed ligands of $\mathrm{N}$-methyl- $\mathrm{N}$ phenyldithiocarbamate and benzoylacetone have been synthesized and characterized by various physicochemical methods. The $\mathrm{Zn}$ complex displayed a four-coordinate geometry, while the remaining complexes ( $\mathrm{Cu}(\mathrm{II}), \mathrm{Co}(\mathrm{II})$, and $\mathrm{Mn}(\mathrm{II})$ ) adopted six-coordinate systems each with two molecules of water as additional ligands. DFT calculations generated some electronic and thermodynamic parameters, which indicates that the $\mathrm{Zn}$ (II) complex has the highest tendency to donate its most energetic electron, while the $\mathrm{Cu}$ (II) complex has the highest tendency to accept electrons from the appropriate occupied orbitals of an electron-donating species. The overall trend of the stability of the metal complexes observed in the present study is $\mathrm{Mn}<\mathrm{Co}<\mathrm{Cu}>\mathrm{Zn}$. The results of the antimicrobial activity studies show that the zinc complex is more effective compared to the other complexes.

\section{Conflict of Interests}

The authors declare that there is no conflict of interests regarding the publication of this paper.

\section{References}

[1] R. Shanmugakala, P. Tharmaraj, C. D. Sheela, and N. Chidambaranathan, "Transition metal complexes of s-triazine derivative: new class of anticonvulsant, anti-inflammatory, and neuroprotective agents," Medicinal Chemistry Research, vol. 23, no. 1, pp. 329-342, 2014.

[2] M. B. Halli, V. B. Patil, R. B. Sumathi, and K. Mallikarjun, "Synthesis, characterization and biological activity of mixed ligand metal (II) complexes derived from benzofuran2-carbohydrazide schiff base and malonyldihydrazide," Der Pharma Chemica, vol. 4, no. 6, pp. 2360-2367, 2012.

[3] R. C. Maurya, P. Sharma, and D. Sutradhar, "Metal thiocyanato complexes: synthesis, magnetic, and spectral studies of some mixed-ligand thiocyanato complexes of nickel(II) involving benzothiazole and benzimidazole derivatives," Synthesis and Reactivity in Inorganic and Metal-Organic Chemistry, vol. 33, no. 3, pp. 387-401, 2003.

[4] Y.-T. Li, C.-W. Yan, C.-Y. Zhu, and H.-S. Guan, "Synthesis and magnetic studies of $\mu$-oxamido-bridged copper(II)manganese(II) heterobinuclear complexes," Synthesis and Reactivity in Inorganic and Metal-Organic Chemistry, vol. 34, no. 7, pp. 1165-1179, 2004.

[5] Y. Aydogdu, F. Yakuphanoglu, A. Aydogdu, E. Tas, and A. Cukurovali, "Solid state electrical conductivity properties of copper complexes of novel oxime compounds containing oxolane ring," Materials Letters, vol. 57, no. 24-25, pp. 37553760, 2003.

[6] S. H. Ramadan, H.-K. Fun, and B. K. Ghosh, "A study on copper(II)-Schiff base-azide coordination complexes: synthesis, $\mathrm{X}$-ray structure and luminescence properties of $\left[\mathrm{Cu}(\mathrm{L})\left(\mathrm{N}_{3}\right)\right] \mathrm{X}$ $\left(\mathrm{L}=\right.$ Schiff bases; $\left.\mathrm{X}=\mathrm{ClO}_{4}, \mathrm{PF}_{6}\right)$," Polyhedron, vol. 24, no. 18, pp. 3091-3097, 2005.

[7] H.-Y. Bie, J.-H. Yu, J.-Q. Xu et al., "Synthesis, structure and non-linear optical property of a copper(II) thiocyanate threedimensional supramolecular compound," Journal of Molecular Structure, vol. 660, no. 1-3, pp. 107-112, 2003.

[8] E. Jóna, M. Kubranová, P. Šimon, and J. Mroziński, “Thermochemical investigation: $\mathrm{Ni}(\mathrm{II})-3$-pyridylcarbinol (ronicol) interactions in solid halogeno and thiocyanato complexes," Journal of Thermal Analysis, vol. 46, no. 5, pp. 1325-1337, 1996.

[9] A. S. Mildvan and M. Cohn, "Kinetic and magnetic resonance studies of the pyruvate kinase reaction: II. complexes of enzyme, 
metal, and substrates," Journal of Biological Chemistry, vol. 241, no. 5, pp. 1178-1193, 1960.

[10] E. Bouwman, W. L. Driessen, and J. Reedijk, "Model systems for type I copper proteins: structures of copper coordination compounds with thioether and azole-containing ligands," Coordination Chemistry Reviews, vol. 104, no. 1, pp. 143-172, 1990.

[11] M. N. Hughes, "Coordination compounds in biology," in Comprehensive Coordination Chemistry, G. Wilkinson, R. D. Gillard, and J. A. McCleverty, Eds., vol. 6, p. 541, Pergamon Press, Oxford, UK, 1987.

[12] N. V. Thakkar and J. R. Thakkar, "Synthesis and characterization of chiral mixed ligand $\mathrm{Co}$ (II) complexes of isonitrosopropiophenone and amino acids," Synthesis and Reactivity in Inorganic and Metal-Organic Chemistry, vol. 30, no. 10, pp. 1871-1887, 2000.

[13] V. S. Shivankar and N. V. Takkar, "Synthesis, characterization and antimicrobial activity of some mixed ligand $\mathrm{Co}(\mathrm{II})$ and Ni(II) complexes," Acta Poloniae Pharmaceutica, vol. 60, no. 1, pp. 45-50, 2003.

[14] R. Kaushal, N. Kumar, A. Chaudhary, S. Arora, and P. Awasthi, "Synthesis, spectral characterization, and antiproliferative studies of mixed ligand titanium complexes of adamantylamine," Bioinorganic Chemistry and Applications, vol. 2014, Article ID 142828, 12 pages, 2014.

[15] O. A. Odunola, M. A. Oladipo, J. A. O. Woods, and A. C. Gelebe, "Synthesis and structural studies of ternary copper(II) complexes containing $\beta$-diketones with 1,10 phenanthraline and $2,2^{\prime}$ bipyridyl and $\mathrm{x}$-ray structure of $\left[\mathrm{Cu}\left(\mathrm{C}_{6} \mathrm{H}_{5} \mathrm{COCHCOCH}_{3}\right)(\right.$ bipy $\left.) \mathrm{Cl}\right]$," Synthesis and Reactivity in Inorganic and Metal-Organic Chemistry, vol. 33, no. 5, pp. 857-871, 2003.

[16] H. Khan, A. Badshah, M. Said et al., "Anticancer metallopharmaceutical agents based on mixed-ligand palladium(II) complexes with dithiocarbamates and tertiary organophosphine ligands," Applied Organometallic Chemistry, vol. 27, no. 7, pp. 387-395, 2013.

[17] R. C. Mehota, R. Bohva, and D. P. Gaur, Metal $\beta$-Diketonates and Allied Derivatives, Academic Press, New York, NY, USA, 1978.

[18] K. C. Joshi and V. N. Pathak, "Metal chelates of fluorinated 1,3-diketones and related compounds," Coordination Chemistry Reviews, vol. 22, no. 1-2, pp. 37-122, 1977.

[19] A. A. Osowole, Synthesis, physicochemical and biological properties of cobalt(II), nickel(II) and copper (II) complexes of various substituted $\beta$-ketoamines and their adducts [Ph.D. thesis], University of Ibadan, 2002.

[20] J. L. Burdett and M. T. Rogers, "Keto-enol tautomerism in $\beta$-dicarbonyls studied by nuclear magnetic resonance spectroscopy. I. Proton chemical shifts and equilibrium constants of pure compounds," Journal of the American Chemical Society, vol. 86, no. 11, pp. 2105-2109, 1964.

[21] R. L. Lintvedt and H. F. Holtzclaw Jr., "Proton magnetic resonance spectra and electronic effects in substituted 1,3diketones," Journal of the American Chemical Society, vol. 88, no. 12, pp. 2713-2716, 1966.

[22] S. Kawaguchi, "Variety in the coordination modes of $\beta$ dicarbonyl compounds in metal complexes," Coordination Chemistry Reviews, vol. 70, pp. 51-84, 1986.

[23] D. W. Thompson and A. L. Allred, "Keto-enol equilibria in 2,4pentanedione and 3,3-dideuterio-2,4-pentanedione," Journal of Physical Chemistry, vol. 75, no. 3, pp. 433-435, 1971.

[24] M. Agrawal, A. Khandelwal, G. Baswal, and S. Bugalia, "Synthesis and spectral studies of mixed ligand complexes of $\mathrm{Mn}$ (III) with 2-hydroxypropiophone and substituted salicylaldehyde or $\beta$-diketones," Journal of Applicable Chemistry, vol. 3, no. 3, pp. 1015-1024, 2014.

[25] K. C. Kemp, E. Fourie, J. Conradie, and J. C. Swarts, "Ruthenocene-containing $\beta$-diketones: synthesis, $\mathrm{pKa}$ ' values, keto-enol isomerization kinetics, and electrochemical aspects," Organometallics, vol. 27, pp. 353-362, 2008.

[26] K. S. Siddiqi, S. A. A. Nami, Lutfullah, and Y. Chebude, "Template synthesis of symmetrical transition metal dithiocarbamates," Journal of the Brazilian Chemical Society, vol. 17, no. 1, pp. 107-112, 2006.

[27] R. Say, E. Birlik, Z. Erdemgil, A. Denizli, and A. Ersöz, "Removal of mercury species with dithiocarbamate-anchored polymer/organosmectite composites," Journal of Hazardous Materials, vol. 150, no. 3, pp. 560-564, 2008.

[28] N. Ünlü and M. Ersoz, "Removal of heavy metal ions by using dithiocarbamated-sporopollenin," Separation and Purification Technology, vol. 52, no. 3, pp. 461-469, 2007.

[29] F. Fu, H. Zeng, Q. Cai, R. Qiu, J. Yu, and Y. Xiong, "Effective removal of coordinated copper from wastewater using a new dithiocarbamate-type supramolecular heavy metal precipitant," Chemosphere, vol. 69, no. 11, pp. 1783-1789, 2007.

[30] Y. Yoshikawa, Y. Adachi, and H. Sakurai, "A new type of orally active anti-diabetic $\mathrm{Zn}(\mathrm{II})$-dithiocarbamate complex," Life Sciences, vol. 80, no. 8, pp. 759-766, 2007.

[31] S. Ozkirimli, T. I. Apak, M. Kiraz, and Y. Yegenoglu, "Synthesis of new triazolyl- $N, N$-dialkyldithiocarbamates as antifungal agents," Archives of Pharmacal Research, vol. 28, no. 11, pp. 12131218, 2005.

[32] F. Shaheen, A. Badshah, M. Gielen, C. Gieck, M. Jamil, and D. de Vos, "Synthesis, characterization, in vitro cytotoxicity and anti-inflammatory activity of palladium(II) complexes with tertiary phosphines and heterocyclic thiolates: crystal structure of $\left[\mathrm{PdC}_{28} \mathrm{H}_{19} \mathrm{~N}_{8} \mathrm{PS}_{2}\right]$," Journal of Organometallic Chemistry, vol. 693, no. 6, pp. 1117-1126, 2008.

[33] V. Alverdi, L. Giovagnini, C. Marzano et al., "Characterization studies and cytotoxicity assays of $\mathrm{Pt}(\mathrm{II})$ and $\mathrm{Pd}(\mathrm{II})$ dithiocarbamate complexes by means of FT-IR, NMR spectroscopy and mass spectrometry," Journal of Inorganic Biochemistry, vol. 98, no. 6, pp. 1117-1128, 2004.

[34] R. Singh and N. K. Kaushik, "Spectral and thermal studies with anti-fungal aspects of some organotin(IV) complexes with nitrogen and sulphur donor ligands derived from 2phenylethylamine," Spectrochimica Acta-Part A: Molecular and Biomolecular Spectroscopy, vol. 71, no. 2, pp. 669-675, 2008.

[35] S. M. Mamba, A. K. Mishra, B. B. Mamba, P. B. Njobeh, M. F. Dutton, and E. Fosso-Kankeu, "Spectral, thermal and in vitro antimicrobial studies of cyclohexylamine- $N$-dithiocarbamate transition metal complexes," Spectrochimica Acta A: Molecular and Biomolecular Spectroscopy, vol. 77, no. 3, pp. 579-587, 2010.

[36] A. Earnshew, Introduction to Magnetochemistry, Academic Press, London, UK, 1980.

[37] A. C. Ekennia, D. C. Onwudiwe, and A. A. Osowole, "Spectral, thermal stability and antibacterial studies of copper, nickel and cobalt complexes of $N$-methyl- $N$-phenyl dithiocarbamate," Journal of Sulfur Chemistry, vol. 36, no. 1, pp. 96-104, 2015.

[38] D. C. Onwudiwe and P. A. Ajibade, "Synthesis and crystal structure of Bis( $N$-alkyl- $N$-phenyl dithiocarbamato)mercury(II)," Journal of Chemical Crystallography, vol. 41, no. 7, pp. 980-985, 2011. 
[39] A. D. Becke, "Density-functional exchange-energy approximation with correct asymptotic behavior," Physical Review A, vol. 38, no. 6, pp. 3098-3100, 1988.

[40] C. Lee, W. Yang, and R. G. Parr, "Development of the ColleSalvetti correlation-energy formula into a functional of the electron density," Physical Review B, vol. 37, no. 2, pp. 785-789, 1988.

[41] I. Georgieva and N. Trendafilova, "Bonding analyses, formation energies, and vibrational properties of $M-R_{2} \mathrm{dtc}$ complexes ( $\mathrm{M}$ $=\mathrm{Ag}(\mathrm{I}), \mathrm{Ni}(\mathrm{II}), \mathrm{Cu}(\mathrm{II})$, or $\mathrm{Zn}(\mathrm{II}))$," The Journal of Physical Chemistry A, vol. 111, no. 50, pp. 13075-13087, 2007.

[42] L. Chen, T. Liu, and C. Ma, "Metal complexation and biodegradation of EDTA and S,S-EDDS: a density functional theory study," Journal of Physical Chemistry A, vol. 114, no. 1, pp. 443454, 2010.

[43] Y. Niu, S. Feng, Y. Ding, R. Qu, D. Wang, and J. Han, "Theoretical investigation on sulfur-containing chelating resindivalent metal complexes," International Journal of Quantum Chemistry, vol. 110, no. 10, pp. 1982-1993, 2010.

[44] S. I. Gorelsky, L. Basumallick, J. Vura-Weis et al., "Spectroscopic and DFT investigation of $\left[\mathrm{MHB}\left(3,5-{ }^{i} \mathrm{Pr}_{2} \mathrm{pz}\right)_{3}\left(\mathrm{SC}_{6} \mathrm{~F}_{5}\right)\right](\mathrm{M}=$ $\mathrm{Mn}, \mathrm{Fe}, \mathrm{Co}, \mathrm{Ni}, \mathrm{Cu}$, and $\mathrm{Zn}$ ) model complexes: periodic trends in metal-thiolate bonding," Inorganic Chemistry, vol. 44, no. 14, pp. 4947-4960, 2005.

[45] M. Belcastro, T. Marino, N. Russo, and M. Toscano, "Interaction of cysteine with $\mathrm{Cu}^{2+}$ and Group IIb $\left(\mathrm{Zn}^{2+}, \mathrm{Cd}^{2+}, \mathrm{Hg}^{2+}\right)$ metal cations: a theoretical study," Journal of Mass Spectrometry, vol. 40, no. 3, pp. 300-306, 2005.

[46] T. Marino, M. Toscano, N. Russo, and A. Grand, "Structural and electronic characterization of the complexes obtained by the interaction between bare and hydrated first-row transitionmetal ions $\left(\mathrm{Mn}^{2+}, \mathrm{Fe}^{2+}, \mathrm{Co}^{2+}, \mathrm{Ni}^{2+}, \mathrm{Cu}^{2+}, \mathrm{Zn}^{2+}\right)$ and glycine," Journal of Physical Chemistry B, vol. 110, no. 48, pp. 2466624673, 2006.

[47] R. Terreux, M. Domard, C. Viton, and A. Domard, "Interactions study between the copper II ion and constitutive elements of chitosan structure by DFT calculation," Biomacromolecules, vol. 7, no. 1, pp. 31-37, 2006.

[48] J. C. Amicangelo, "Theoretical characterization of a tridentate photochromic Pt(II) complex using density functional theory methods," Journal of Chemical Theory and Computation, vol. 3, no. 6, pp. 2198-2209, 2007.

[49] F. Tarazona-Vasquez and P. B. Balbuena, "Dendrimertetrachloroplatinate precursor interactions. 1. Hydration of Pt(II) species and PAMAM outer pockets," Journal of Physical Chemistry A, vol. 111, no. 5, pp. 932-944, 2007.

[50] F. Tarazona-Vasquez and P. B. Balbuena, "Dendrimertetrachloroplatinate precursor interactions. 2. Noncovalent binding in PAMAM outer pockets," Journal of Physical Chemistry A, vol. 111, no. 5, pp. 945-953, 2007.

[51] T. H. Dunning Jr. and P. J. Hay, Modern Theoretical Chemistry, edited by H. F. Schaefer III, Plenum, New York, NY, USA, 1976.

[52] P. J. Hay and W. R. Wadt, "Ab initio effective core potentials for molecular calculations. Potentials for the transition metal atoms Sc to Hg," The Journal of Chemical Physics, vol. 82, no. 1, pp. 270283, 1985.

[53] W. R. Wadt and P. J. Hay, “Ab initio effective core potentials for molecular calculations. Potentials for main group elements $\mathrm{Na}$ to Bi," The Journal of Chemical Physics, vol. 82, no. 1, pp. 284298, 1985.

[54] P. J. Hay and W. R. Wadt, "Ab initio effective core potentials for molecular calculations. Potentials for $\mathrm{K}$ to Au including the outermost core orbitale," The Journal of Chemical Physics, vol. 82, no. 1, pp. 299-310, 1985.

[55] J. Sabolović, C. S. Tautermann, T. Loerting, and K. R. Liedl, "Modeling anhydrous and aqua copper(II) amino acid complexes: a new molecular mechanics force field parametrization based on quantum chemical studies and experimental crystal data," Inorganic Chemistry, vol. 42, no. 7, pp. 2268-2279, 2003.

[56] M. Y. Combariza and R. W. Vachet, "Effect of coordination geometry on the gas-phase reactivity of four-coordinate divalent metal ion complexes," Journal of Physical Chemistry A, vol. 108, no. 10, pp. 1757-1763, 2004.

[57] M. A. Carvajal, J. J. Novoa, and S. Alvarez, "hoice of coordination number in $\mathrm{d}^{10}$ complexes of group 11 metals," Journal of the American Chemical Society, vol. 126, no. 5, pp. 1465-1477, 2004.

[58] B. D. Alexander and T. J. Dines, "Ab initio calculations of the structures and vibrational spectra of ethene complexes," Journal of Physical Chemistry A, vol. 108, no. 1, pp. 146-156, 2004.

[59] M. J. Frisch, G. W. Trucks, H. B. Schlegel et al., Gaussian 09, Revision D.01, Gaussian, Wallingford, Conn, USA, 2009.

[60] A. A. Nejo, G. A. Kolawole, M. C. Dumbele, and A. R. Opoku, "Spectral, magnetic, biological, and thermal studies of metal (II) complexes of some unsymmetrical Schiff bases," Journal of Coordination Chemistry, vol. 63, no. 24, pp. 4367-4379, 2010.

[61] M. Tunçel and S. Serin, "Synthesis and characterization of copper(II), nickel(II) and cobalt(II) complexes with azo-linked schiff base ligands," Synthesis and Reactivity in Inorganic, MetalOrganic, and Nano-Metal Chemistry, vol. 35, no. 3, pp. 203-212, 2005.

[62] S. M. E. Khalil, H. S. Seleem, B. A. El-Shetary, and M. Shebl, "Mono- and bi-nuclear metal complexes of schiff-base hydrazone $(\mathrm{ONN})$ derived from o-hydroxyacetophenone and 2-amino-4-hydrazino-6-methyl pyrimidine," Journal of Coordination Chemistry, vol. 55, no. 8, pp. 883-899, 2002.

[63] A. Earnshaw, The Introduction to Magnetochemistry, Academic Press, New York, NY, USA, 1980.

[64] F. A. Cotton, G. Wilkinson, C. A. Murillo, and M. Bochmann, Advanced Inorganic Chemistry, John Wiley \& Sons, New York, NY, USA, 1999.

[65] N. S. R. Koteswara Rao and M. G. R. Reddy, "Studies on the synthesis, characterisation and antimicrobial activity of new $\mathrm{Co}(\mathrm{II}), \mathrm{Ni}(\mathrm{II})$ and $\mathrm{Zn}(\mathrm{II})$ complexes of Schiff base derived from ninhydrin and glycine," Biology of Metals, vol. 3, no. 1, pp. 19-23, 1990.

[66] S. M. Abu-el Wafa and R. M. Issa, "The preparation of a series of $\mathrm{Mn}(\mathrm{II})$ complexes of the type $\left[\mathrm{Mn}(\mathrm{SB}) \mathrm{SO}_{2}\right]$," Bulletin de la Société Chimique de France, vol. 5, pp. 595-598, 1989.

[67] A. A. Osowole, A. A. Oni, K. Onyegbula, and A. T. Hassan, "Synthesis, spectral, magnetic and in-vitro anticancer properties of some metal (II) complexes of 3-[2,4-dihydro-1H-inden4-ylimino) methyl] napthalene-2-ol," International Research Journal of Pure and Applied Chemistry, vol. 2, no. 3, pp. 211-220, 2012.

[68] W. J. Geary, "The use of conductivity measurements in organic solvents for the characterisation of coordination compounds," Coordination Chemistry Reviews, vol. 7, no. 1, pp. 81-122, 1971.

[69] IUPAC, Compendium of Chemical Terminology, Gold Book, 2nd edition, 1997.

[70] T. C. Higgs, K. Spartalian, C. J. O’Connor, B. F. Matzanke, and C. J. Carrano, "Synthesis and characterization of a series of edge-sharing octahedral-tetrahedral octahedral linear trinuclear complexes $\left[\mathrm{M}_{3}(\mathrm{L1O})_{4}\right]^{2+}$, where $\mathrm{M}=\mathrm{Mn}^{2+}, \mathrm{Co}^{2+}, \mathrm{Ni}^{2+}$, 
$\mathrm{Cu}^{2+}$, and $\mathrm{Zn}^{2+}$ and $\mathrm{LiOH}$ is the 'Heteroscorpionate' ligand (2hydroxyphenyl)bis(pyrazolyl)methane," Inorganic Chemistry, vol. 37, pp. 2263-2272, 1998.

[71] D. Sun, R. Cao, Y. Liang, Q. Shi, W. Su, and M. Hong, "Hydrothermal syntheses, structures and properties of terephthalate-bridged polymeric complexes with zig-zag chain and channel structures," Journal of the Chemical Society, Dalton Transactions, vol. 16, pp. 2335-2340, 2001.

[72] E. Ruiz, J. Cirera, and S. Alvarez, "Spin density distribution in transition metal complexes," Coordination Chemistry Reviews, vol. 249, no. 23, pp. 2649-2660, 2005.

[73] J. Cano, E. Ruiz, S. Alvarez, and M. Verdaguer, "Spin density distribution in transition metal complexes: some thoughts and hints," Comments on Inorganic Chemistry, vol. 20, no. 1, pp. 2756, 1998.

[74] H. Irving and R. J. P. Williams, "The stability of transition-metal complexes," Journal of the Chemical Society, vol. 8, pp. 31923210, 1953.

[75] G. W. Luther, D. T. Rickard, S. Theberge, and A. Olroyd, "Determination of metal (Bi)sulfide stability constants of $\mathrm{Mn}^{2+}$, $\mathrm{Fe}^{2+}, \mathrm{Co}^{2+}, \mathrm{Ni}^{2+}, \mathrm{Cu}^{2+}$, and $\mathrm{Zn}^{2+}$ by voltammetric methods," Environmental Science and Technology, vol. 30, no. 2, pp. 671679, 1996.

[76] A. A. Osowole, I. Ott, and O. M. Ogunlana, "Synthesis, spectroscopic, anticancer, and antimicrobial properties of some Metal(II) complexes of (substituted) nitrophenol schiff base," International Journal of Inorganic Chemistry, vol. 2012, Article ID 206417, 6 pages, 2012. 

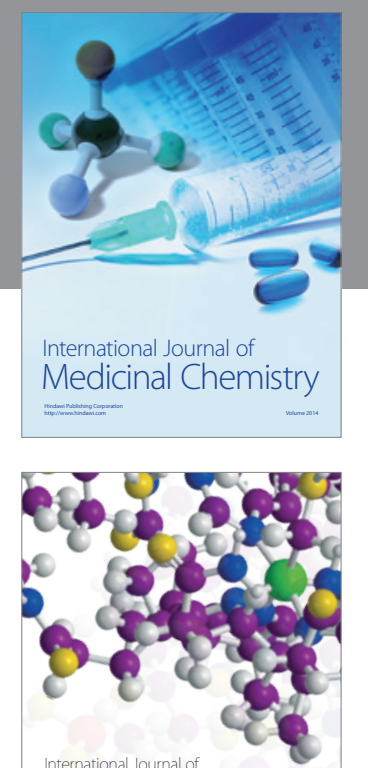

\section{Carbohydrate} Chemistry

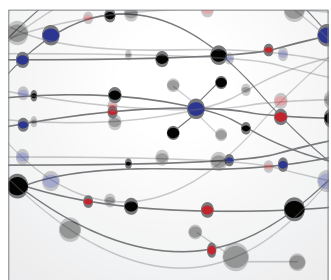

The Scientific World Journal
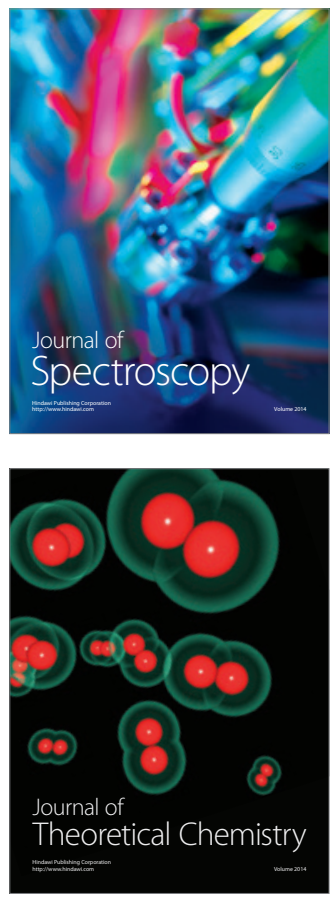
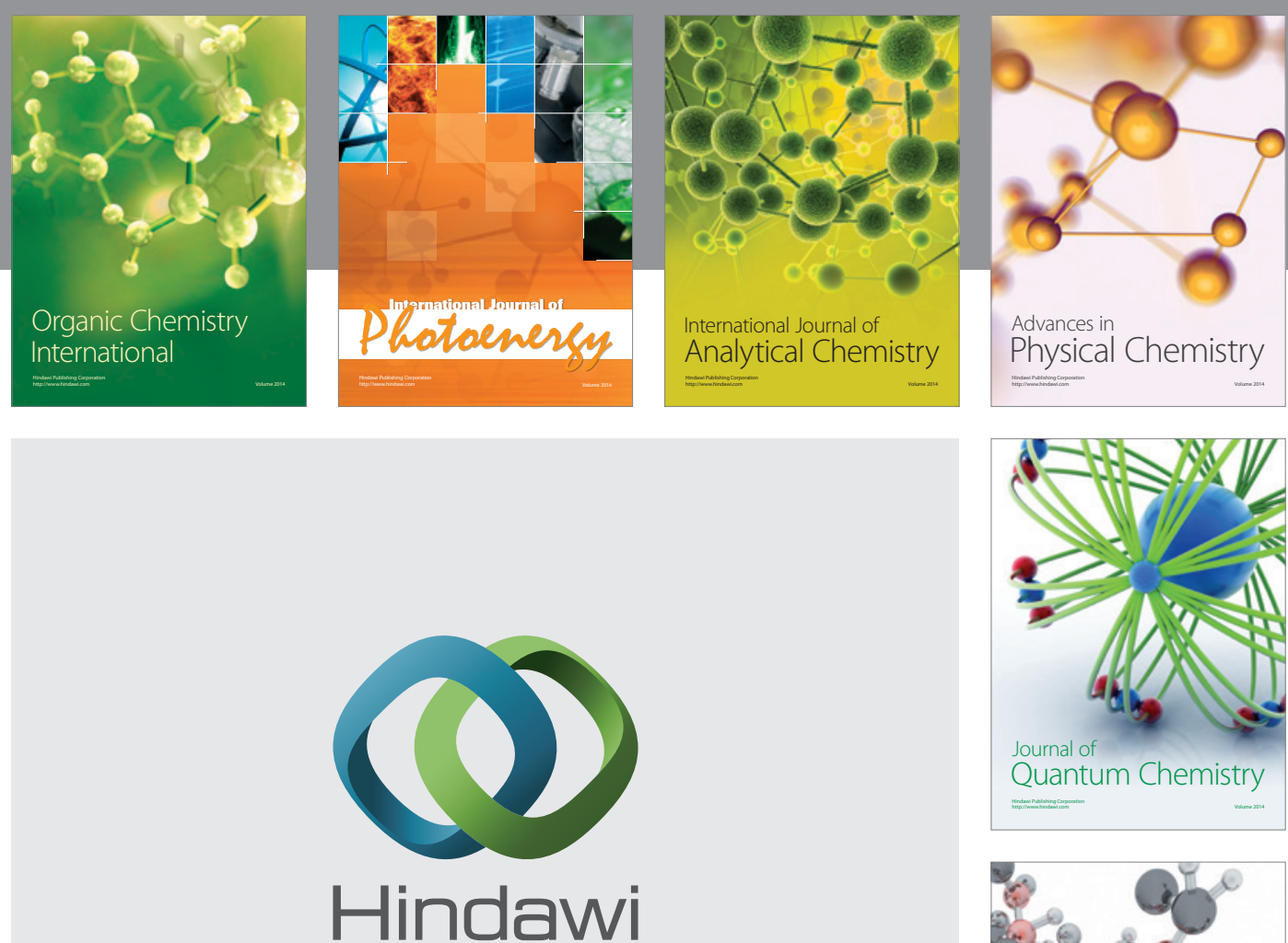

Submit your manuscripts at

http://www.hindawi.com

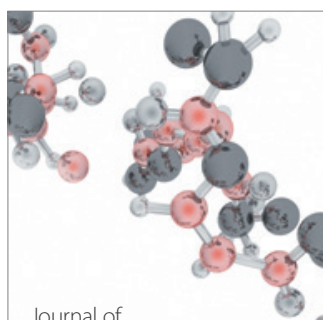

Analytical Methods

in Chemistry

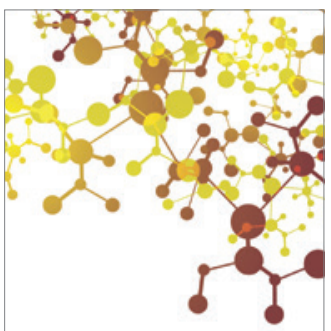

Journal of

Applied Chemistry

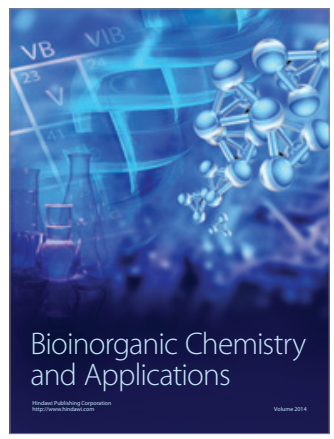

Inorganic Chemistry
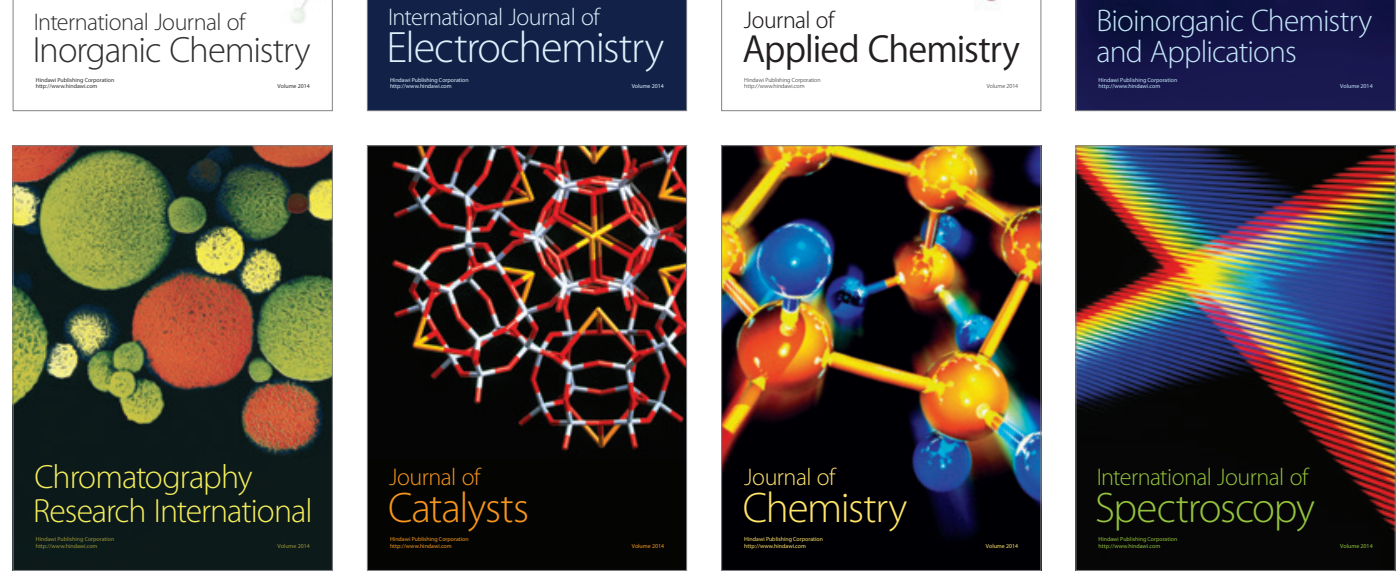